2 Biphenyls in a HepG2 Cell Culture System: Experimental

\title{
and Modeling Results
}

4

5

11 Corresponding Author:

12 Dr. Hans-Joachim Lehmler

13 The University of Iowa

14 Department of Occupational and Environmental Health

15 University of Iowa Research Park, B164 MTF

16 Iowa City, IA 52242-5000

17 Phone: (319) 335-4981

18 Fax: (319) 335-4290

19 e-mail: hans-joachim-lehmler@uiowa.edu

\author{
Iowa 52242, United States
}


21 Cell culture studies are used to study the toxicity of polychlorinated biphenyls (PCBs);

22 however, it is typically unknow how much PCB enters the cells. We investigated the partitioning

23 of chiral PCBs (PCB 91, PCB 95, PCB 132, or PCB 136) in the human hepatoma HepG2 cell

24 line. We used a computational model for the in vitro to in vivo extrapolation (IVIVE) of PCB

25 levels. HepG2 cells were incubated with PCBs for 72 h. PCB levels were quantified in cells,

26 media, and cell culture dishes. PCBs were present in cell culture medium (60.7-88.8 \%), cells

27 (8.0-14.6\%), and dishes (2.3-7.8 \%), and displayed atropisomeric enrichment in cells

28 (enantiomeric fraction $[\mathrm{EF}]=0.55-0.77)$ and dishes $(\mathrm{EF}=0.53-0.68)$. The free $\mathrm{PCB}$ concentration

29 in media, estimated using polyparameters linear free energy relationships (PP-LFERs) and a

30 composition-based model, was used to extrapolate from the nominal PCB concentration used in

31 vitro to PCB tissue levels and vice versa. This approach allows for an IVIVE but does not

32 account for the atropselective partitioning of chiral PCBs between medium and cells. Because

33 PCB atropisomers differ in their toxicities, the atropselectively partitioning of PCBs between

34 culture medium and cells needs to be considered when interpreting cell culture-derived data. 


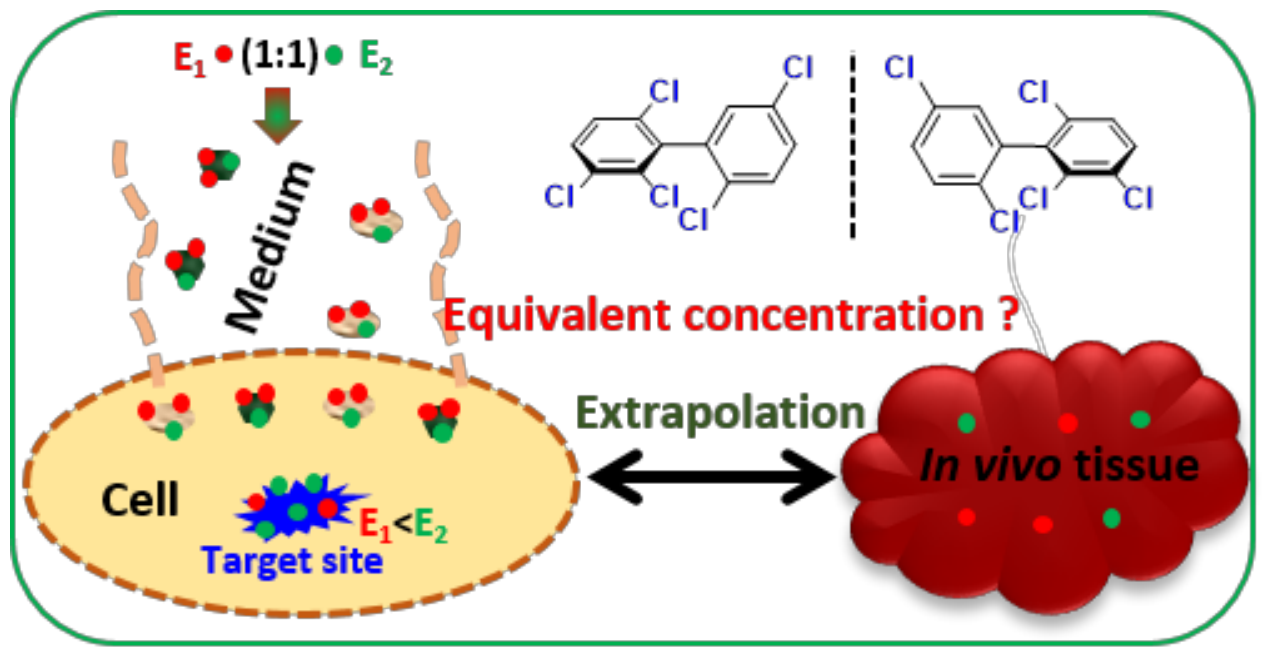



PCBs pose an environmental and human health hazard, the Stockholm Convention has banned the production of PCBs worldwide. Besides, parties to the Convention have committed to stop

41 the use of PCBs in technical applications, such as transformers and capacitors, by 2025 and to

42 dispose of legacy PCBs in an environmentally sound manner by $2028 .^{2}$ However, some PCBs are 43 still produced unintentionally and can be found in consumer products, such as paint and resins. ${ }^{3-5}$

44 Moreover, PCBs are still present in building materials and can contaminate the indoor air of 45 buildings, such as schools. ${ }^{6,7}$ Biomonitoring studies demonstrate that PCB levels in human food, 46 human serum and environmental samples, such as fish livers, only slightly decreased over the 47 last two decades. ${ }^{8-10}$ Overall, PCBs represent a significant and current public health concern.

48 Exposure to PCBs has been linked to a range of adverse human health outcomes, including cancer, immunotoxicity, cardiovascular disease, and developmental neurotoxicity. ${ }^{11}$ PCB

50 congeners with multiple ortho substituents have been implicated in the developmental

51 neurotoxicity of PCBs. ${ }^{12}$ Several of these neurotoxic PCB congeners display axial chirality and

52 exist as stable rotational isomers, or atropisomers, which are non-superimposable mirror images

53 of each other. Chiral PCB congeners are enantioselectively metabolized to potentially neurotoxic

54 hydroxylated and sulfated metabolites, ${ }^{13,}{ }^{14}$ resulting in an atropisomeric enrichment of both the

55 parent PCB and its metabolites in environmental samples, wildlife, and humans. ${ }^{13,15}$ These

56 findings are toxicologically relevant because PCB atropisomers can atropselectively affect

57 biological targets in the liver and brain. PCB atropisomers atropselectively affect the expression

58 of drug-metabolizing enzymes in the rat liver, ${ }^{16,17}$ and bind atropselectively to cytochrome P450 
enzymes. ${ }^{18}$ Pure atropisomers of PCBs 95 and 136 selectively affect endpoints involved in PCB

60 developmental neurotoxicity by mechanisms involving ryanodine receptors (RyRs). ${ }^{19-21}$

61 These in vitro models are a powerful tool to study chiral PCBs, either as a racemic mixture or

62 individual atropisomers. However, it remains challenging to extrapolate from the nominal PCB

63 concentrations used in in vitro studies to in vivo tissue concentrations and vice versa. We posit

64 that the free concentration of PCBs (i.e., the PCB concentration not bound to proteins and lipids)

65 can be used for IVIVE because only the free PCB concentration is available for partitioning into

66 or out of cells. ${ }^{22,23}$ Because it is challenging to measure the free concentration of chemicals

67 experimentally, several models have been developed to connect their nominal concentration to

68 the free concentration using the quantities and sorptive capacities of each biological component

69 (i.e., protein, lipid, and water). ${ }^{22,24-26}$ The free concentration in the aqueous phase $\left(C_{f r e e}\right)$ can be

70 calculated from nominal concentration $\left(C_{\text {nominal }}\right)$ using the general mass balance equation as

71 follows:

72

$$
C_{\text {free }}=\frac{C_{\text {nominal }} V_{\text {medium }}}{\sum K_{i / \text { water }} V_{i}}
$$

73 where $i$ represents the sorptive components, including protein, lipid, water, etc. When the

74 sorptive component $i$ is water, the partitioning coefficient $K_{i / \text { water }}$ equals to $1 . V_{\text {medium }}$ is the

75 volume of medium and $V_{i}$ is the volume of component $i$.

76 The $C_{\text {free }}$ calculated for the in vitro bioassay can subsequently be used for IVIVE to estimate

77 tissue levels $\left(C_{\text {tissue }}\right)$ in vivo with the following equation:

78

$$
C_{\text {tissue }}=C_{\text {free }} \sum K_{i / \text { water }} f_{i}
$$

79 where $f_{i}$ is the volume fraction of the biological component $i$ in vivo. The quantities of the 80 biological components in vitro and in vivo can be determined experimentally or are available from 
81 the literature. ${ }^{22,} 27$ In addition, $K_{i}$ water can be measured or estimated from the octanol/water

82 partition coefficient $\left(K_{o w}\right)^{23,24}$ or PP-LFERs. ${ }^{22,27}$ These data are readily available for all 209 PCB 83 congeners. ${ }^{28}$

84 This study characterized the partitioning of PCB 91, PCB 95, PCB 132, and PCB 136, four 85 environmentally and toxicologically relevant chiral PCBs, ${ }^{13}, 14$ in a HepG2 cell culture model in

86

87

the absence of detectable PCB metabolism. The free concentration of PCBs in the cell culture model was estimated, either based on the PCB levels measured in the medium at the endpoint or added in the beginning using a PP-LFER composition-based model. Because the experimentbased and theoretical free PCB concentrations showed a reasonable agreement, the PP-LFERbased free concentrations were used to extrapolate the nominal PCB concentration of all 209 PCB congeners in the HepG2 cell culture assays to tissue levels and vice versa. While this approach allows a straightforward IVIVE, it does not account for the enantioselective partitioning of chiral PCBs between medium and cells. Importantly, typical concentrations used in cell culture studies are frequently higher than equivalent tissue concentrations.

\section{EXPERIMENTAL SECTION}

Materials. 2,2',3,5’6-Pentachlorobiphenyl (PCB 95), 2,2',3,3’,6,6'-hexachlorobiphenyl (PCB 136), 4'-chloro-3'-fluoro-4-sulfooxy-biphenyl (3-F,4'-PCB 3 sulfate, surrogate of PCB metabolites), 4'-chloro-3'-fluoro-4-hydroxy-biphenyl (3-F,4'-OH-PCB 3, surrogate of PCB metabolites) were synthesized and authenticated as previously described. ${ }^{29,} 30$ 2,2',3,4'6Pentachlorobiphenyl (PCB 91), 2,2’,3,3’,4,6’-hexachlorobiphenyl (PCB 132), 2,3,4’,5,6pentachlorobiphenyl (PCB 117, recovery standard for PCBs), 2,3,3’,4,5,5’-hexachlorobiphenyl4’-ol (4'-OH-PCB 159, recovery standard for OH-PCBs) and 2,2',3,4,4’,5,6,6’-

octachlorobiphenyl (PCB 204, internal standard) were purchased from AccuStandard, Inc. (New 
Haven, CT, USA). Analytical standards of OH-PCBs and methylated derivatives of OH-PCBs were synthesized and authenticated as reported earlier (for additional information, see Table S1). ${ }^{31}$ Solutions of diazomethane in diethyl ether were prepared from $N$-methyl- $N$-nitroso-ptoluenesulfonamide (Diazald) using an Aldrich mini Diazald apparatus (Milwaukee, WI, USA).

Sulfatase (type H-2 from Helix pomatia, $\geq 2000$ units $/ \mathrm{mL}$ ) for the deconjugating of potential hydroxylated PCB conjugates and resazurin sodium salt were purchased from Sigma-Aldrich (St Louis, MO, USA). Phenol red-free minimum essential medium (MEM), fetal bovine serum (FBS), L-glutamine, glucose solution, penicillin/streptomycin (P/S), Dulbecco’s phosphatebuffered saline (PBS), trypsin-EDTA, Costar 6- and 24-well plates, as well as dimethyl sulfoxide (DMSO), were obtained from Thermo Fisher Scientific (Radnor, PA, USA).

HepG2 cells were purchased from the American Type Culture Collection (ATCC; Manassas, VA, USA). The authenticity of the human hepatocellular carcinoma cell line HepG2 was confirmed by analysis of genomic DNA conducted by the University of Arizona Genetics Core (Arizona Research laboratories, Tucson, AZ, USA). The HepG2 cells used in this study were between passages 18 through 35. Cells were maintained in complete medium (MEM supplemented with $10 \%$ FBS, $100 \mathrm{U} / \mathrm{mL}$ penicillin, $100 \mu \mathrm{g} / \mathrm{mL}$ streptomycin, and $2 \mathrm{mM} \mathrm{l-}$ glutamine) in a humidified incubator with $5 \% \mathrm{CO}_{2}$ at $37^{\circ} \mathrm{C}$. Exposure medium contained MEM with $10 \%$ FBS was supplemented with $100 \mathrm{U} / \mathrm{mL}$ penicillin, $100 \mu \mathrm{g} / \mathrm{mL}$ streptomycin, and 2 mM l-glutamine. PCBs (i.e., PCB 91, PCB 95, PCB 132, and PCB 136) were dissolved in DMSO. The final concentration of DMSO in the medium did not exceed $0.1 \%(\mathrm{v} / \mathrm{v})$. This DMSO concentration did not have any effect on cell viability.

PCBs exposure of HepG2 cells. HepG2 cells (6×10\%/well) were seeded into 6-well plates with $3 \mathrm{~mL}$ complete medium per well. After $48 \mathrm{~h}$ attachment, cells were exposed in triplicates to 
0.25, 1 or $10 \mu \mathrm{M}$ of the racemic PCB 91, PCB 95, PCB 132, and PCB 136 (0.1 \% DMSO) in exposure medium (3 mL). The control group was exposed to $0.1 \%$ DMSO in triplicates in the exposure medium. After a $72 \mathrm{~h}$ incubation, the medium was carefully transferred into weighted glass vials, and the cells were washed once with PBS (1 mL). This solution was combined with the exposure medium. The cells were harvested into PBS $(1 \mathrm{~mL})$ with a rubber policeman and added into a weighted glass vial. The wells were washed once with PBS (1 mL), and the washing solution was combined with the cell suspension. All vials were stored at $-20{ }^{\circ} \mathrm{C}$ until analysis.

The plates were wrapped in aluminum foil and stored at $4{ }^{\circ} \mathrm{C}$ until analysis. The cytotoxicities of PCBs at concentrations of $0.25 \mu \mathrm{M}$ and $10 \mu \mathrm{M}$ are summarized in Fig. S1.

In separate experiments, cell-free plates with $10 \mu \mathrm{M}$ of the racemic PCBs in exposure medium or $0.25 \mu \mathrm{M}$ of the racemic PCBs in MEM were also incubated for $72 \mathrm{~h}$, and samples were processed as described above to study the partitioning of PCBs in the cell culture wells in the absence of cells.

\section{Extraction of PCBs and their metabolites from media, cell pellets, and dishes. Depending} on the PCB concentrations, different extraction workflows were used for media, cell pellets, and dish samples (Fig. S2). The extraction of media samples (0.25 and $10 \mu \mathrm{M})$ and cell pellets samples (0.25 $\mu \mathrm{M}$ only) was described previously, with minor modidfication. ${ }^{32-34}$ Briefly, samples were spiked with PCB 117 (100 ng in isooctane) and 4’-OH-PCB 159 (50 ng in methanol) and acidified with hydrochloric acid to protonate OH-PCBs (6 M, $1 \mathrm{~mL}$ ). The samples were extracted with hexane/MTBE (1:1 v/v, $5 \mathrm{~mL})$, 2-propanol (5 mL) was added, and samples were re-extracted with hexane (3 mL). The combined organic phases were washed with a potassium chloride solution ( $1 \% \mathrm{w} / \mathrm{v}, 4 \mathrm{~mL})$, the organic phase was evaporated to dryness under a gentle stream of nitrogen, and the sample was reconstituted in hexane $(1 \mathrm{~mL})$. The extract was 
150 derivatized using diazomethane in ethyl ether $(0.5 \mathrm{~mL})$ overnight at $4{ }^{\circ} \mathrm{C},{ }^{35}$ and subjected to

151 sulfur removal and sulfuric acid clean-up steps as described. ${ }^{36,37}$ After extraction with

152 hexane/MTBE, the medium samples (10 $\mu \mathrm{M}$ PCB exposure groups only) were deconjugated

153 with sulfatase (type H-2 from Helix pomatia) as described in the Supporting Information to

154 assess the presence of sulfate or glucuronide conjugates in the cell culture media. PCB 204 (100

155 ng) was added as an internal standard (volume corrector) before the gas chromatographic

156 analysis. $^{36,37}$

157 Cell culture dishes were allowed to dry, PCB 117 (100 ng in isooctane) was added, and all

158 dishes were washed twice with hexane $(4 \mathrm{~mL}$ and $3 \mathrm{~mL}){ }^{20}$ The hexane phase was cleaned up as

159 described above for media and cell pellets samples.

160 Untargeted analyses were performed with media samples from the $1 \mu \mathrm{M}$ PCB exposure

161 groups. Briefly, media samples were extracted with acetonitrile, and the resulting extracts were

162 screened for the presence of PCB metabolites by Ultra-Performance Liquid Chromatography-

163 Quadrupole Time-of-flight Mass Spectrometry (UPLC-QTof-MS) as described in the Supporting

164 Information.

165 Quantitative gas chromatographic analyses of PCBs and their metabolites. Quantitative

166 analysis of PCBs and OH-PCBs (as methylated derivatives) in sample extracts was carried out on

167 an Agilent 7890A gas chromatograph (GC) equipped with an SPB-1 capillary column (60 m

168 length, $250 \mu \mathrm{m}$ inner diameter, $0.25 \mu \mathrm{m}$ film thickness; Supelco, St Louis, MO, USA) and a

$169{ }^{63} \mathrm{Ni}$-micro electron capture detector $(\mu \mathrm{ECD})$ as previously reported. ${ }^{32,33}$ Helium was used as

170 carrier gas with a constant flow rate of $2 \mathrm{~mL} / \mathrm{min}$. The temperature program was as follows:

171 initial temperature $50{ }^{\circ} \mathrm{C}$ for $1 \mathrm{~min}, 30^{\circ} \mathrm{C} / \mathrm{min}$ to $200{ }^{\circ} \mathrm{C}, 1{ }^{\circ} \mathrm{C} / \mathrm{min}$ to $250{ }^{\circ} \mathrm{C}, 10^{\circ} \mathrm{C} / \mathrm{min}$ to 280

$172{ }^{\circ} \mathrm{C}$, and hold for $3 \mathrm{~min}$. The PCBs were identified based on their retention time, with relative 
173 retention times (RRT) being within $0.5 \%$ of the RRT of the respective PCBs standard. ${ }^{38}$ PCBs

174 were quantified with the internal standard using the relative response factors in both samples and

175 the reference standard mixture. PCB levels were corrected for the recovery of the surrogate

176 recovery standard to account for any loss of PCBs during the extraction. The hydroxylated PCB

177 metabolites (as methylated derivatives) listed in Table S1 were not detected in any sample.

178 Atropselective gas chromatographic analyses of PCBs. Enantioselective analyses of PCBs

179 were employed by an Agilent 6890 gas chromatograph (GC) equipped with a ${ }^{63} \mathrm{Ni}-\mu \mathrm{ECD}$

180 detector and CP-Chirasil Dex CB (CD) (25 m length, $250 \mu \mathrm{m}$ inner diameter, $0.25 \mu \mathrm{m}$ film

181 thickness; Agilent, Santa Clara, CA, USA) or Cyclosil-B (CB) (30 m length, $250 \mu \mathrm{m}$ inner

182 diameter, $0.25 \mu \mathrm{m}$ film thickness; Agilent) capillary columns. ${ }^{39-41}$ The flow rate of the carrier

183 gas, helium, was $3 \mathrm{~mL} / \mathrm{min}^{34,39,40,42}$ The temperature program for the atropselective analysis of

184 PCB 91, PCB 95 and PCB 136 was as follows: initial temperature $50{ }^{\circ} \mathrm{C}$ for $1 \mathrm{~min}, 10{ }^{\circ} \mathrm{C} / \mathrm{min}$ to

$185140{ }^{\circ} \mathrm{C}$, hold for $170 \mathrm{~min}, 15^{\circ} \mathrm{C} / \mathrm{min}$ to $200{ }^{\circ} \mathrm{C}$, and hold for $20 \mathrm{~min}$. The column temperature

186 program for the atropselective analysis of PCB 132 was as follows: initial temperature $50{ }^{\circ} \mathrm{C}$ for

$1871 \mathrm{~min}, 10^{\circ} \mathrm{C} / \mathrm{min}$ to $160{ }^{\circ} \mathrm{C}$, hold for $140 \mathrm{~min}, 15^{\circ} \mathrm{C} / \mathrm{min}$ to $200{ }^{\circ} \mathrm{C}$, and hold for $20 \mathrm{~min}$. The

188 enantiomeric fraction (EF) was determined with the drop valley method and calculated as EF =

189 Area $E_{1} /\left(\right.$ Area $E_{1}+$ Area $\left.E_{2}\right)$, where Area $E_{1}$ and Area $E_{2}$ are the peak areas of the atropisomer

190 eluting first and second on the chiral column. ${ }^{34,39,40,42}$ A summary of the EF values on different

191 columns is provided in Table S2.

192 Quality assurance/quality control (QA/QC). The responses of the electron capture detector

193 were linear from 1 to $1000 \mathrm{ng} / \mathrm{mL}$ for all the analytes. Method blanks and matrix blanks (media, 194 cell pellets, and dishes) were analyzed in parallel with all samples. Besides, samples from control

195 incubations were analyzed in parallel, including blank incubations with HepG2 cells exposed to 
$0.1 \%$ DMSO only and blank, cell-free incubations containing only MEM medium and $0.1 \%$

DMSO. The quality assurance/quality control (QA/QC) data, including the limits of detection

(LODs) of PCBs, the PCB background levels calculated from the matrix blanks, the recoveries of surrogate standard (PCB 117) for all samples, resolution of the PCB atropisomers, and the EF values of the racemic standards, are summarized in Table S3.

Equilibrium partitioning model in the cell culture system. Building on a published, composition-based model, ${ }^{22}$ we predicted the partitioning of the PCBs in the cell culture system by accounting for the well-documented differences in the partitioning of PCBs into different lipid classes (Fig. S3). ${ }^{43}, 44$ In our four-component model, both the cell and medium compartments were assumed to consist of albumin protein, membrane lipid, storage lipid, and water. Assuming a partition equilibrium between the compartments in the cell culture system, the free concentration of PCBs can be calculated from the initial amount of PCB added into the incubation $\left(m_{0}\right)$ and the sorptive capacities of the biological components in both medium and cells using the following equation (for more details, see the Supporting Information):

$$
C_{\text {free }}=\frac{m_{0}}{K_{a p, w}\left(V_{m, a p}+V_{c, a p}\right)+K_{m l, w}\left(V_{m, m l}+V_{c, m l}\right)+K_{s l, w}\left(V_{m, s l}+V_{c, s l}\right)+V_{m, w}+V_{c, w}}
$$

211 where $K_{a p, w}, K_{m l, w}$ and $K_{s l, w}$ are the partition coefficients of PCBs between protein and water,

212 membrane lipid and water, and storage lipid and water, respectively; $V_{m, a p}, V_{m, m l}, V_{m, s l}$ and

$213 V_{m, w}$ are the phase volumes of albumin protein, membrane lipid, storage lipid and water in the 214 medium; $V_{c, a p}, V_{c, m l}, V_{c, s l}$ and $V_{c, w}$ are the phase volumes of protein, membrane lipid, storage 215 lipid, and water in cells. The $m_{0}$ values used for the model calculations were corrected by 216 subtracting the measured levels of PCBs absorbed to the cell culture dishes. The partition 217 coefficients of PCBs used for the calculations were obtained from established PP-LFERs. ${ }^{27}$ The 
218 solvation parameters used for the PP-LFERs ${ }^{28}$ and other parameters needed for the model

219 predictions were obtained from published literature values (Table S4). ${ }^{22,45,46}$

220 For comparison, the free concentration of PCBs in the cell culture system was calculated from

221 the measured PCBs levels in medium $\left(m_{\text {medium }}\right)$ and the sorptive capacities of the biological

222 components in medium (for more details, see the Supporting Information), i.e.,

$$
C_{\text {free }}=\frac{m_{\text {medium }}}{K_{a p, w} V_{m, a p}+K_{m l, w} V_{m, m l}+K_{s l, w} V_{m, s l}+V_{m, w}}
$$

In vitro-in vivo extrapolation of PCB levels. The $C_{\text {free }}$ values from the cell culture

225

226

227

228

229

230

231 and were obtained from established PP-LFERs. ${ }^{27}$ All the volume fractions were obtained from

experiments were used to calculate equivalent PCBs levels in the liver and plasma with a composition-based model for describing in vivo systems. In this model, the biological components in both plasma and liver are albumin proteins, muscle proteins, storage lipids, membrane lipids, and water. ${ }^{27}$ The equivalent PCBs levels in liver and plasma can be expressed as (for more details, see the Supporting Information)

$$
C_{\text {liver }}=C_{\text {free }}\left(K_{a p, w} f_{l, a p}+K_{m p, w} f_{l, m p}+K_{m l, w} f_{l, m l}+K_{s l, w} f_{l, s l}+f_{l, w}\right)
$$

$$
C_{\text {plasma }}=C_{f r e e}\left(K_{a p, w} f_{p, a p}+K_{m p, w} f_{p, m p}+K_{m l, w} f_{p, m l}+K_{s l, w} f_{p, s l}+f_{p, w}\right)
$$

respectively. $K_{m p, w}$ is the partition coefficient of PCBs between muscle protein and water. $f_{l, a p}$, $f_{l, m p}, f_{l, m l}, f_{l, s l}$ and $f_{l, w}$ are the volume fractions of albumin proteins, muscle proteins, membrane lipids, storage lipids, and water in the liver, respectively. $f_{p, a p}, f_{p, m p}, f_{p, m l}, f_{p, s l}$ and $f_{p, w}$ are the volume fractions of albumin proteins, muscle proteins, membrane lipids, storage lipids, and water in plasma, respectively. The partitioning coefficients of PCBs used for the calculations literature data. ${ }^{27}$ 
metabolize environmental pollutants, such as PAHs and others, ${ }^{47-49}$ it is also well documented

243 that, compared to primary human hepatocytes and hepatospheres, HepG2 cells express lower

244 levels of xenobiotic processing enzymes, ${ }^{50}$ including cytochrome P450 isoforms involved in the 245 metabolism of chiral PCBs. ${ }^{40}$ Cells were exposed for $72 \mathrm{~h}$ to these four PCB congeners $(0.25 \mu \mathrm{M}$ or $10 \mu \mathrm{M}$ ) to assess if HepG2 cells can metabolize PCB 91, PCB 95, PCB 132 and PCB 136.

247 Cell culture media and cell pellets were extracted and analyzed for PCB metabolites using 248 targeted and untargeted approaches (Fig. S2). No hydroxylated, sulfated, glucuronidated, or other 249 metabolites were detected in any sample. This finding is not surprising because PCB metabolism 250 decreases with increasing degree of chlorination and is expected to be relatively low for the 251 penta- and hexa-chlorinated PCB congeners investigated. ${ }^{51}$

252 Quantitative distribution of PCBs in the HepG2 cell culture system. We quantified the 253 PCBs levels in cell culture media, cells, and dishes in the absence of detectable PCB metabolism 254 after PCBs incubation with and without HepG2 cells for 72 h (Fig. 1). Large percentages (60 to $89 \%)$ of PCBs were recovered from the cell culture medium supplemented with $10 \%$ FBS.

256 Only 7.9 to $14.7 \%$ of the PCBs were associated with the cell pellets. Approximately $6 \%$ (2.3 to

$257 \quad 7.8 \%$ ) of PCBs were absorbed onto the cell culture dishes, both for incubations with and without 258 cells. The percentage of the two hexachlorinated congeners was higher in the medium than the 259 percentage of the pentachlorinated congeners. This finding is consistent with an increasing 260 affinity of PCBs for serum proteins, such as albumin, with an increasing degree of chlorination. 261 Similarly, an in vitro study showed that the binding affinity of PCBs for binding site II of 262 albumin, the major protein in FBS, increases with an increase in the number of chlorine atoms. ${ }^{52}$ 
263 The PCB mass ratios between cell pellets : media : dishes were $1: 4.9$ : 0.54 for pentachlorinated

264 congeners and $1: 8.6: 0.37$ for hexachlorinated congeners, respectively. These ratios are

265 comparable to earlier studies. For example, the PCB ratios between cell pellets : media : dishes

266 for a lower chlorinated PCB congener, PCB 11, were $1: 7.8$ : 3.3 for 100 nM PCB 11, $1: 8.5$ :

2672.3 for $1 \mu \mathrm{M}$ PCB 11 , and $1: 5.0: 1.2$ for $10 \mu \mathrm{M}$ PCB 11 in a primary cortical cell culture

268 model..$^{53}$ Another study with primary rat hippocampal neurons reported a mass ratio of PCB 136

269 between cells and media of $1: 14 .^{20}$

270 Modeling the partitioning of PCBs in the HepG2 cell culture system. Studies with cells in

271 culture typically report only the nominal concentrations of a toxicant, such as PCBs, and not the

272 fraction of the toxicant that partitions into the cells. Thus, it is challenging to extrapolate from

273 concentrations used in in vitro studies to tissue levels from in vivo studies. The amount of the

274 toxicant in cells depends on its free concentration in the aqueous cell culture medium and the

275 cells; however, the experimental determinations of the free concentration of a toxicant are

276 challenging. Several composition-based models have been developed to predict the partitioning

277 of different chemicals in microsomal incubations ${ }^{25}$ and cell culture models, ${ }^{22}$ with the goal of

278 relating nominal concentrations to free concentrations. However, these models have not been

279 used to estimate the free concentrations of PCBs in vitro.

280 We employed a four-phase, composition-based model to describe the equilibrium partitioning 281 of PCBs between cells and medium (Fig. 2a). This model is based on several assumptions: First, 282 both cell culture medium and cells contain four biological components (i.e., protein, storage 283 lipid, membrane lipid, and water). Second, PCBs have reached a partition equilibrium between 284 proteins and water and between lipids and water. Third, the sorptive fractions (proteins, lipids, 285 etc.) in medium change only insignificantly during the incubation. We used this model to predict 
286 the free concentrations of the PCBs from both the initial amount of PCBs added in cell culture

287 (Eq. 3) and the measured amount of PCBs in the medium after harvesting (Eq. 4). We employed

288 different permutations of published experimental values for the biological components in cell

289 culture medium and HepG2 cells because these values can show considerable variability (Table

290 S3). Both methods estimated similar free concentrations of PCBs (Fig. 2b). It is, therefore,

291 possible to approximate the free concentration of PCBs in cell culture-based assays based on

292 their nominal concentrations and published experimental values for the biological components in

293 the cell culture medium and the cells (Table S4).

294 In vitro to in vivo extrapolation. We used the free PCB concentrations from our in vitro

295 predictions, determined with Eq. 3, to extrapolate from the nominal PCB concentrations to PCB

296 tissue concentrations with a published IVIVE model. ${ }^{23}$ Based on this model, the PCB tissue

297 levels equivalent to the in vitro concentrations $(0.25 \mu \mathrm{M})$ were $500 \pm 60,490 \pm 70,560 \pm 80$ and

$298580 \pm 80 \mathrm{ng} / \mathrm{g}$ plasma and 6,200 $\pm 800,6,100 \pm 800,7,200 \pm 1,000$ and 7,700 $\pm 1,100 \mathrm{ng} / \mathrm{g}$ liver wet

299 weight for PCB 91, PCB 95, PCB 132 and PCB 136 in vivo, respectively (Fig. 3a). Furthermore,

300 IVIVE coefficients, defined as the ratio of the PCB level in vivo (i.e., plasma or liver levels as

$301 \mathrm{ng} / \mathrm{g}$ wet weight) over the nominal concentration (in $\mu \mathrm{M}$ ) in the cell culture experiments, were

302 calculated. The IVIVE coefficients were 2,000 $\pm 300,2,000 \pm 300,2,200 \pm 300$ and 2,300 \pm 300 for

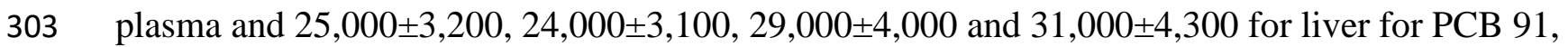

304 PCB 95, PCB 132 and PCB 136, respectively (Table 1). These plasma IVIVE coefficients

305 demonstrate that blood PCB levels are a poor rationale for the selection of nominal concentration

306 for cell culture-based toxicity studies.

307 The IVIVE model also allowed us to estimate nominal concentrations for cell culture

308 experiments that are equivalent to the PCB tissue levels observed in vivo. For example, liver 
tissues levels of 1,800 ng/g for PCB 91, 1,200 ng/g for PCB 95 and 410 ng/g for PCB 136 observed in mice exposed orally to racemic PCBs ${ }^{54-56}$ correspond to nominal concentrations of 73 nM PCB 91, 49 nM PCB 95 and 13 nM PCB 136 in studies in HepG2 cells. Based on these estimations, the micromolar PCB concentrations employed in our study $(0.25 \mu \mathrm{M})$ are 4 to 14 times higher than the equivalent levels of the in vivo observations, even though micromolar concentrations are commonly used in in vitro studies. ${ }^{47,48}$ The model also enabled us to predict IVIVE extrapolation coefficients for all 209 PCBs for the experimental conditions employed in the present study (Fig. 3b). As expected, the extrapolation coefficients increased with an increasing degree of chlorination for plasma and liver. Relevant experimental parameters (e.g., cell number, medium volume, medium composition, etc.) are readily available from the published literature or can be determined experimentally. Thus, it is relatively easy to calculate similar extrapolation coefficients for other experimental systems using the spreadsheet provided in the Supporting Information.

\section{Atropselective partitioning of PCBs in the HepG2 cell culture system. The PCB congeners} investigated in this project bind atropselectively to cytochrome P450 enzymes ${ }^{40}$ and undergo atropselective metabolism in the liver. ${ }^{37,55,56}$ Although this has not been studied previously, it is likely that PCBs interact enantioselectively with serum proteins, such as albumin. Therefore, we also assessed the atropselective partitioning of PCBs in our cell culture model.

Significant atropisomeric enrichment was detected in media, cells, and dishes for the four PCB congeners (Figs. 4\&5). The atropisomer eluting first on a CD column $\left(E_{1}\right)$ was significantly enriched in both cells and dishes for PCB 91 (i.e., (-)-PCB 91, ${ }^{57}$; EF values of 0.77 for cells and 0.68 for dishes), PCB 132 (i.e., (-)-PCB 132 ${ }^{58}$; EF values of 0.69 for cells and 0.63 for dishes), and PCB 136 (i.e., (-)-PCB 136 ${ }^{58}$; EF values of 0.55 for cells and 0.68 for dishes). A slight 
332 enrichment of $\mathrm{E}_{1}$-PCB 95 (i.e., aR- or (-)-PCB 95 ${ }^{59}$ ) was observed, with EF values of 0.55 for 333 cells and 0.53 for dishes.

334 The E2-atropisomers of PCB 91, PCB 132 and PCB 136 were enriched in the cell culture 335 medium, with EF values of 0.41, 0.44, and 0.47, respectively (Figs. 4\&5). The PCB 95 residue 336 was near racemic in the cell culture media samples, possibly because its high concentrations 337 masked the atropisomeric enrichment. In parallel experiments, chiral analysis of samples from 338 cell-free incubations revealed near-racemic chiral signatures in both dish and media samples 339 (Fig. S4). These findings suggest that chiral PCBs enantioselectively partition between medium 340 and cells in the HepG2 cell culture system in the absence of detectable PCB metabolism.

341 Because we did not observe an atropselective partitioning in cell-free incubations, the 342 atropisomeric enrichment appears to be driven by the selective partitioning of PCB atropisomers 343 into the HepG2 cells.

344 Metabolism studies with human liver microsome showed a depletion of $(+)$-PCB 91, ${ }^{42}(+)-$ 345 PCB 95 34 and (-)-PCB 132, ${ }^{60}$ whereas (+)-PCB 91, (+)-PCB 95 and (+)-PCB 132 were enriched 346 in HepG2 cells. These observations suggest that the enantioselective partitioning of PCBs in 347 biological systems is determined by the complex biological components of cells and tissues. In 348 contrast, only a small portion of enzymes (i.e., the active site of cytochrome P450 enzymes) is 349 responsible for the subsequent atropselective metabolism of PCBs observed in in vitro 350 metabolism studies. ${ }^{34,40,42,60}$ Consistent with this interpretation, we have demonstrated that the 351 binding of PCB 136 atropisomers to rat cytochrome P450 enzymes ${ }^{18}$ does not predict the 352 atropselective metabolism of racemic PCB 136 by rat liver microsomes. ${ }^{33}$

353 The results for the enantioselective analyses demonstrate that in vitro metabolism and toxicity 354 studies with chiral compounds, including PCBs, should take their enantioselective partitioning 
355 into account. Moreover, current composition-based models can not accurately describe the

356 partitioning of chiral compounds in biological systems because they used the same chemical

357 descriptors for the enantiomers; however, these models can be modified to incorporate

358 enantioselective interactions with proteins (e.g., albumin or cytochrome P450 enzymes) and

359 enantioselective metabolism.

360 CONFLICT OF INTEREST STATEMENT

361 The authors declare no competing financial interest.

362 FUNDING SOURCES

363 This work was supported by grants ES027169, ES013661, and ES005605 from the National

364 Institute of Environmental Health Sciences, National Institutes of Health. The content is solely

365 the responsibility of the authors and does not necessarily represent the official views of the

366 National Institute of Environmental Health Sciences or the National Institutes of Health.

367 ACKNOWLEDGMENTS

368 Thanks to Dr. Lynn Teesch and Mr. Vic Parcell (High-Resolution Mass Spectrometry

369 Facility, University of Iowa) for help with the chemical analysis, and Drs. Ram Dhakal, Xueshu

$370 \mathrm{Li}$, Xianran He, and Wenjin Xu (University of Iowa) for the synthesis of PCB metabolite 371 standards. 


\section{SUPPORTING INFORMATION}

373 Details regarding the deconjugation procedures, untargeted analysis, mathematic details of

374 the partitioning models, chemical standards, enantiomeric fractions, quality assurance/quality

375 control data, biological compositions, cytotoxicity data, overall extraction workflow, sorptive

376 capacities of chemicals, and partitioning of PCBs in cell-free incubations. This material is

377 available free of charge via the Internet at http://pubs.acs.org. 


\section{REFERENCES}

379 1. Fiedler, H.; Abad, E.; van Bavel, B.; de Boer, J.; Bogdal, C.; Malisch, R. The need for capacity building and first results for the Stockholm Convention Global Monitoring Plan. Trac-Trend Anal Chem 2013, 46, 72-84.

382

2. PCBs-overview. http://www.pops.int/Implementation/IndustrialPOPs/PCB/Overview/tabid/273/Default.aspx (Accessed on Mar 19, 2020),

3. Hu, D.F.; Hornbuckle, K.C. Inadvertent polychlorinated biphenyls in commercial paint pigments. Environ Sci Technol 2010, 44, 2822-2827.

387

4. Herkert, N.J.; Jahnke, J.C.; Hornbuckle, K.C. Emissions of tetrachlorobiphenyls (PCBs 47, 51, and 68) from polymer resin on kitchen cabinets as a non-aroclor source to residential air. Environ Sci Technol 2018, 52, 5154-5160.

5. Anezaki, K.; Kannan, N.; Nakano, T. Polychlorinated biphenyl contamination of paints containing polycyclic- and Naphthol AS-type pigments. Environ Sci Pollut Res 2015, 22, 14478-14488.

6. Marek, R.F.; Thome, P.S.; Herkert, N.J.; Awad, A.M.; Hornbuckle, K.C. Airborne PCBs and OHPCBs inside and outside urban and rural US schools. Environ Sci Technol 2017, 51, 7853-7860.

394 7. Gabrio, T.; Piechotowski, I.; Wallenhorst, T.; Klett, M.; Cott, L.; Friebel, P.; Link, B.; Schwenk, 395 M. PCB-blood levels in teachers, working in PCB-contaminated schools. Chemosphere 2000, 40, $396 \quad 1055-1062$.

397 8. Banyiova, K.; Cerna, M.; Mikes, O.; Komprdova, K.; Sharma, A.; Gyalpo, T.; Cupr, P.; Scheringer, 398 M. Long-term time trends in human intake of POPs in the Czech Republic indicate a need for 399 continuous monitoring. Environ Int 2017, 108, 1-10.

400 9. Raffetti, E.; Speziani, F.; Donato, F.; Leonardi, L.; Orizio, G.; Scarcella, C.; Apostoli, P.; Magoni, 401 M. Temporal trends of polychlorinated biphenyls serum levels in subjects living in a highly polluted area from 2003 to 2015: a follow-up study. Int J Hyg Envir Heal 2017, 220, 461-467. 
10. Boitsov, S.; Grosvik, B.E.; Nesje, G.; Malde, K.; Klungsoyr, J. Levels and temporal trends of persistent organic pollutants (POPs) in Atlantic cod (Gadus morhua) and haddock (Melanogrammus aeglefinus) from the southern Barents Sea. Environ Res 2019, 172, 89-97.

11. ATSDR Toxic Substances Portal - Polychlorinated Biphenyls (PCBs). https://www.atsdr.cdc.gov/ToxProfiles/tp.asp?id=142\&tid=26 (Accessed on Mar 19, 2020),

12. Pessah, I.N.; Cherednichenko, G.; Lein, P.J. Minding the calcium store: Ryanodine receptor activation as a convergent mechanism of PCB toxicity. Pharmacol Therapeut 2010, 125, 260-285.

13. Lehmler, H.J.; Harrad, S.J.; Huhnerfuss, H.; Kania-Korwel, I.; Lee, C.M.; Lu, Z.; Wong, C.S. Chiral polychlorinated biphenyl transport, metabolism, and distribution: A review. Environ Sci Technol 2010, 44, 2757-2766.

14. Kania-Korwel, I.; Lehmler, H.J. Chiral polychlorinated biphenyls: absorption, metabolism and excretion-a review. Environ Sci Pollut Res 2016, 23, 2042-2057.

15. Konishi, Y.; Kakimoto, K.; Nagayoshi, H.; Nakano, T. Trends in the enantiomeric composition of polychlorinated biphenyl atropisomers in human breast milk. Environ Sci Pollut R 2016, 23, 20272032.

16. Rodman, L.E.; Shedlofsky, S.I.; Swim, A.T.; Robertson, L.W. Effects of polychlorinated-biphenyls on cytochrome-P450 induction in the chick-embryo hepatocyte culture. Arch Biochem Biophys 1989, 275, 252-262.

17. Puttmann, M.; Mannschreck, A.; Oesch, F.; Robertson, L. Chiral effects in the induction of drugmetabolizing-enzymes using synthetic atropisomers of polychlorinated-Biphenyls (PCBs). Biochem Pharmacol 1989, 38, 1345-1352.

18. Kania-Korwel, I.; Hrycay, E.G.; Bandiera, S.M.; Lehmler, H.J. 2,2 ',3,3 ',6,6 '-hexachlorobiphenyl (PCB 136) atropisomers interact enantioselectively with hepatic microsomal cytochrome P450 enzymes. Chem Res Toxicol 2008, 21, 1295-1303. 
427 19. Pessah, I.N.; Lehmler, H.J.; Robertson, L.W.; Perez, C.F.; Cabrales, E.; Bose, D.D.; Feng, W. 428 Enantiomeric specificity of (-)-2,2 ',3,3 ',6,6 '-hexachlorobiphenyl toward ryanodine receptor types 4291 and 2. Chem Res Toxicol 2009, 22, 201-207.

$430 \quad 20 . \quad$ Yang, D.R.; Kania-Korwel, I.; Ghogha, A.; Chen, H.; Stamou, M.; Bose, D.D.; Pessah, I.N.; Lehmler, H.J.; Lein, P.J. PCB 136 atropselectively alters morphometric and functional parameters of neuronal connectivity in cultured rat hippocampal neurons via ryanodine receptor-dependent mechanisms. Toxicol Sci 2014, 138, 379-392.

434 21. Feng, W.; Zheng, J.; Robin, G.; Dong, Y.; Ichikawa, M.; Inoue, Y.; Mori, T.; Nakano, T.; Pessah, 435 I.N. Enantioselectivity of 2,2 ',3,5 ',6-pentachlorobiphenyl (PCB 95) atropisomers toward ryanodine receptors (RyRs) and their influences on hippocampal neuronal networks. Environ Sci Technol 2017, 51, 14406-14416.

$438 \quad 22 . \quad$ Fischer, F.C.; Henneberger, L.; Konig, M.; Bittermann, K.; Linden, L.; Goss, K.U.; Escher, B.I. Modeling exposure in the Tox21 in vitro bioassays. Chem Res Toxicol 2017, 30, 1197-1208.

440 23. Gulden, M.; Seibert, H. In vitro in vivo extrapolation: estimation of human serum concentrations of chemicals equivalent to cytotoxic concentrations in vitro (vol 189, pg 211, 2003). Toxicology

443 24. Armitage, J.M.; Wania, F.; Arnot, J.A. Application of mass balance models and the chemical activity concept to facilitate the use of in vitro toxicity data for risk assessment. Environ Sci Technol 2014, 48, 9770-9779.

446 25. Poulin, P.; Haddad, S. Microsome composition-based model as a mechanistic tool to predict 447 nonspecific binding of drugs in liver microsomes. J Pharm Sci-Us 2011, 100, 4501-4517.

448 26. Poulin, P.; Haddad, S. Hepatocyte composition-based model as a mechanistic tool for predicting 449 the cell suspension: Aqueous phase partition coefficient of drugs in in vitro metabolic studies. $J$ Pharm Sci-Us 2013, 102, 2806-2818. 
$451 \quad 27 . \quad$ Endo, S.; Brown, T.N.; Goss, K.U. General model for sstimating partition coefficients to organisms and their tissues using the biological compositions and polyparameter linear free energy relationships. Environ Sci Technol 2013, 47, 6630-6639.

454 28. van Noort, P.C.M.; Haftka, J.J.H.; Parsons, J.R. Updated Abraham solvation parameters for 455 polychlorinated biphenyls. Environ Sci Technol 2010, 44, 7037-7042.

456 29. Dhakal, K.; He, X.R.; Lehmler, H.J.; Teesch, L.M.; Duffel, M.W.; Robertson, L.W. Identification 457 of sulfated metabolites of 4-chlorobiphenyl (PCB3) in the serum and urine of male rats. Chem Res $458 \quad$ Toxicol 2012, 25, 2796-2804.

459 30. Shaikh, N.S.; Parkin, S.; Lehmler, H.J. The ullmann coupling reaction: A new approach to 460

31. Joshi, S.N.; Vyas, S.M.; Duffel, M.W.; Parkin, S.; Lehmler, H.J. Synthesis of sterically hindered 462 polychlorinated biphenyl derivatives. Synthesis-Stuttgart 2011, 1045-1054.

463 32. Kania-Korwel, I.; Duffel, M.W.; Lehmler, H.J. Gas chromatographic analysis with chiral 464 cyclodextrin phases reveals the enantioselective formation of hydroxylated polychlorinated biphenyls by rat liver microsomes. Environ Sci Technol 2011, 45, 9590-9596.

466 33. Wu, X.A.; Pramanik, A.; Duffel, M.W.; Hrycay, E.G.; Bandiera, S.M.; Lehmler, H.J.; KaniaKorwel, I. 2,2 ',3,3 ',6,6 '-Hexachlorobiphenyl (PCB 136) Is Enantioselectively Oxidized to Hydroxylated Metabolites by Rat Liver Microsomes. Chem Res Toxicol 2011, 24, 2249-2257.

34. Uwimana, E.; Li, X.S.; Lehmler, H.J. 2,2 ',3,5 ',6-Pentachlorobiphenyl (PCB 95) is atropselectively metabolized to para-hydroxylated metabolites by human liver microsomes. Chem Res Toxicol

472 35. Kania-Korwel, I.; Zhao, H.X.; Norstrom, K.; Li, X.S.; Hornbuckle, K.C.; Lehmler, H.J. 473 Simultaneous extraction and clean-up of polychlorinated biphenyls and their metabolites from 474 small tissue samples using pressurized liquid extraction. J Chromatogr A 2008, 1214, 37-46.

475 36. Kania-Korwel, I.; Hornbuckle, K.C.; Peck, A.; Ludewig, G.; Robertson, L.W.; Sulkowski, W.W.; 476 Espandiari, P.; Gairola, C.G.; Lehmler, H.J. Congener-specific tissue distribution of aroclor 1254 
and a highly chlorinated environmental PCB mixture in rats. Environ Sci Technol 2005, 39, 35133520.

479 37. Kania-Korwel, I.; Shaikh, N.S.; Hornbuckle, K.C.; Robertson, L.W.; Lehmler, H.J. Enantioselective disposition of PCB 136 (2,2 ',3,3 ',6,6 '-hexachlorobiphenyl) in C57BL/6 mice after oral and intraperitoneal administration. Chirality 2007, 19, 56-66.

482 38. Commission, E. Commission Decision EC 2002/657 of 12 August 2002 implementing Council Directive 96/23/EC concerning the performance of analytical methods and the interpretation of results. Off. J. Eur. Communities: Legis 2002, 221.

39. Uwimana, E.; Maiers, A.; Li, X.S.; Lehmler, H.J. Microsomal metabolism of prochiral 486

40. Uwimana, E.; Ruiz, P.; Li, X.S.; Lehmler, H.J. Human CYP2A6, CYP2B6, AND CYP2E1 atropselectively metabolize polychlorinated biphenyls to hydroxylated metabolites. Environ Sci Technol 2019, 53, 2114-2123.

41. Kania-Korwel, I.; El-Komy, M.H.M.E.; Veng-Pedersen, P.; Lehmler, H.J. Clearance of polychlorinated biphenyl atropisomers is enantioselective in female C57Bl/6 mice. Environ Sci Technol 2010, 44, 2828-2835.

494 42. Uwimana, E.; Li, X.S.; Lehmler, H.J. Human liver microsomes atropselectively metabolize 2,2 495 ',3,4 ',6-pentachlorobiphenyl (PCB 91) to a 1,2-shift product as the major metabolite. Environ Sci Technol 2018, 52, 6000-6008.

497 43. Geisler, A.; Endo, S.; Goss, K.U. Partitioning of organic chemicals to storage lipids: Elucidating the dependence on fatty acid composition and temperature. Environ Sci Technol 2012, 46, 95199524.

500 44. Endo, S.; Escher, B.I.; Goss, K.U. Capacities of membrane lipids to accumulate neutral organic 501 chemicals. Environ Sci Technol 2011, 45, 5912-5921. 
45. Zhu, X.P.; Yan, H.M.; Xia, M.F.; Chang, X.X.; Xu, X.; Wang, L.; Sun, X.Y.; Lu, Y.; Bian, H.; Li, X.Y.; Gao, X. Metformin attenuates triglyceride accumulation in HepG2 cells through decreasing

46. Cheever, M.; Master, A.; Versteegen, R.J. A method for differentiating fetal bovine serum from

47. Huang, M.; Zhang, L.; Mesaros, C.; Zhang, S.H.; Blaha, M.A.; Blair, I.A.; Penning, T.M. 508

49. Zhang, H.N.; Shao, X.J.; Zhao, H.Z.; Li, X.N.; Wei, J.T.; Yang, C.X.; Caio, Z.W. Integration of

50. Hart, S.N.; Li, Y.; Nakamoto, K.; Subileau, E.A.; Steen, D.; Zhong, X.B. A comparison of whole

51. Grimm, F.A.; Hu, D.F.; Kania-Korwel, I.; Lehmler, H.J.; Ludewig, G.; Hornbuckle, K.C.; Duffel, Metabolism of a representative oxygenated polycyclic aromatic hydrocarbon (PAH) phenanthrene9,10-quinone in human hepatoma (HepG2) cells. Chem Res Toxicol 2014, 27, 852-863.

48. Huang, M.; Zhang, L.; Mesaros, C.; Hackfeld, L.C.; Hodge, R.P.; Bair, I.A.; Penning, T.M. Metabolism of an alkylated polycyclic aromatic hydrocarbon 5-methylchrysene in human hepatoma (HepG2) cells. Chem Res Toxicol 2015, 28, 2045-2058.

metabolomics and lipidomics reveals metabolic mechanisms of triclosan-induced toxicity in human hepatocytes. Environ Sci Technol 2019, 53, 5406-5415.

genome gene expression profiles of HepaRG cells and HepG2 cells to primary human hepatocytes and human liver tissues. Drug Metab Dispos 2010, 38, 988-994.

M.W.; Bergman, A.; Robertson, L.W. Metabolism and metabolites of polychlorinated biphenyls. Crit Rev Toxicol 2015, 45, 245-272.

52. Rodriguez, E.A.; Li, X.; Lehmler, H.J.; Robertson, L.W.; Duffel, M.W. Sulfation of lower chlorinated polychlorinated biphenyls increases their affinity for the major drug-binding sites of human serum albumin. Environ Sci Technol 2016, 50, 5320-5327.

53. Sethi, S.; Keil, K.P.; Chen, H.; Hayakawa, K.; Li, X.; Lin, Y.; Lehmler, H.J.; Puschner, B.; Lein, P.J. Detection of 3,3'-dichlorobiphenyl in human maternal plasma and its effects on axonal and dendritic growth in primary rat neurons. Toxicol Sci 2017, 158, 401-411. 
54. Wu, X.N.; Barnhart, C.; Lein, P.J.; Lehmler, H.J. Hepatic metabolism affects the atropselective disposition of 2,2 ',3,3 ',6,6 '-hexachlorobiphenyl (PCB 136) in mice. Environ Sci Technol 2015, 49, 616-625.

55. Kania-Korwel, I.; Barnhart, C.D.; Stamou, M.; Truong, K.M.; El-Komy, M.H.M.E.; Lein, P.J.; Veng-Pedersen, P.; Lehmler, H.J. 2,2 ',3,5 ',6-Pentachlorobiphenyl (PCB 95) and its hydroxylated metabolites are enantiomerically enriched in female mice. Environ Sci Technol 2012, 46, 1139311401.

56. Wu, X.; Zhai, G.; Schnoor, J.L.; Lehmler, H.J. Atropselective disposition of 2,2',3,4',6pentachlorobiphenyl (PCB 91) and identification of its metabolites in mice with liver-specific deletion of cytochrome P450 reductase. Chem Res Toxicol 2019.

57. He, Z.Y.; Wang, Y.H.; Zhang, Y.W.; Cheng, H.Y.; Liu, X.W. Stereoselective bioaccumulation of chiral PCB 91 in earthworm and its metabolomic and lipidomic responses. Environ Pollut 2018, 238, 421-430.

58. Haglund, P.; Wiberg, K. Determination of the gas chromatographic elution sequences of the (+)and (-)-enantiomers of stable atropisomeric PCBs on Chirasil-Dex. Hrc-J High Res Chrom 1996, 19, 373-376.

59. Nagayoshi, H.; Kakimoto, K.; Konishi, Y.; Kajimura, K.; Nakano, T. Determination of the human cytochrome P450 monooxygenase catalyzing the enantioselective oxidation of 2,2',3,5',6pentachlorobiphenyl (PCB 95) and 2,2',3,4,4',5',6-heptachlorobiphenyl (PCB 183). Environ Sci Pollut Res 2018, 25, 16420-16426.

60. Uwimana, E.; Cagle, B.; Yeung, C.; Li, X.S.; Patterson, E.V.; Doorn, J.A.; Lehmler, H.J. Atropselective oxidation of 2,2 ',3,3 ',4,6 '-hexachlorobiphenyl (PCB 132) to hydroxylated metabolites by human liver microsomes and its implications for PCB 132 neurotoxicity. Toxicol Sci 2019, 171, 406-420. 
(a)

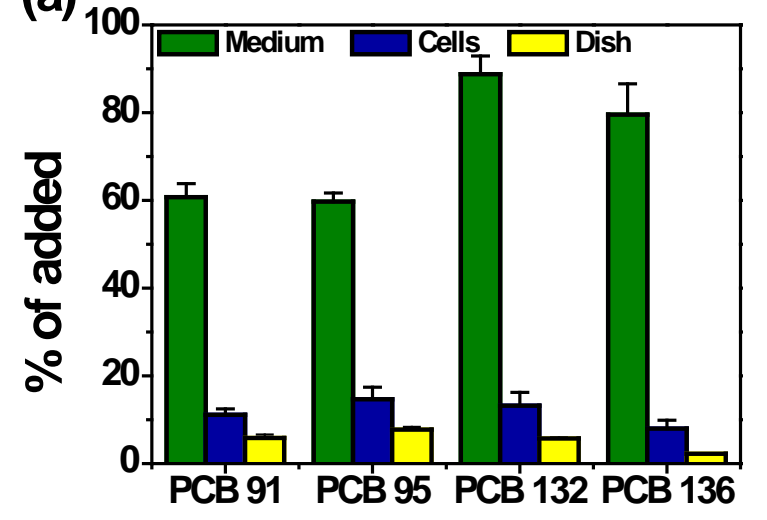

(b)

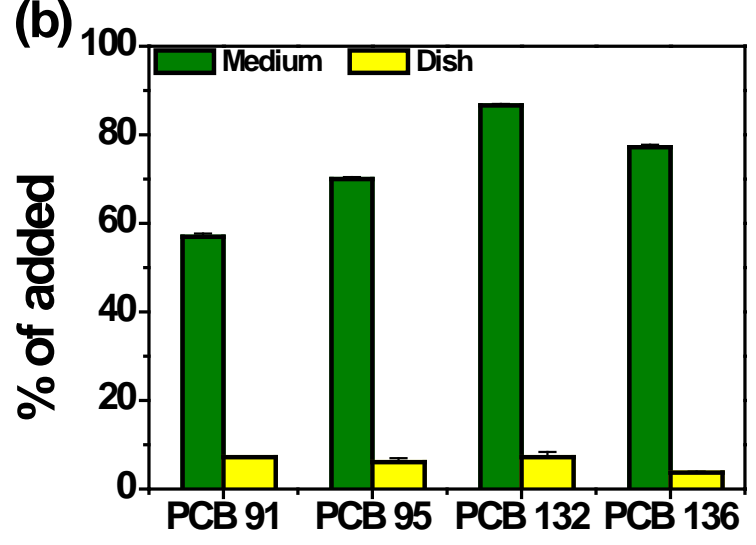

553 Fig. 1. PCB 91, PCB 95, PCB 132, and PCB 136 were primarily present in the cell culture medium

554 from experiments (a) with or (b) without HepG2 cells. Only a small percentage of the PCBs were 555 recovered from the cell pellet (7.9 to $14.7 \%$ ) or the cell culture dish (2.2 to $7.8 \%$ ). HepG2 cells $556\left(6 \times 10^{6} /\right.$ well $)$ were seeded into 6-well plates with complete MEM medium $(3 \mathrm{~mL})$ per well and 557 allowed to attach for $48 \mathrm{~h}$. Cells were exposed for $72 \mathrm{~h}$ to the individual PCB congeners $(0.25 \mu \mathrm{M}$; $0.1 \%$ DMSO) in exposure medium ( $3 \mathrm{~mL}$ ) with $10 \%$ FBS. Controls were exposed to $0.1 \%$ DMSO 559 in the exposure medium. After the incubation, the media, cell pellets, and cell culture dishes were 560 collected, and PCB levels were determined as described in the Experimental Section. 

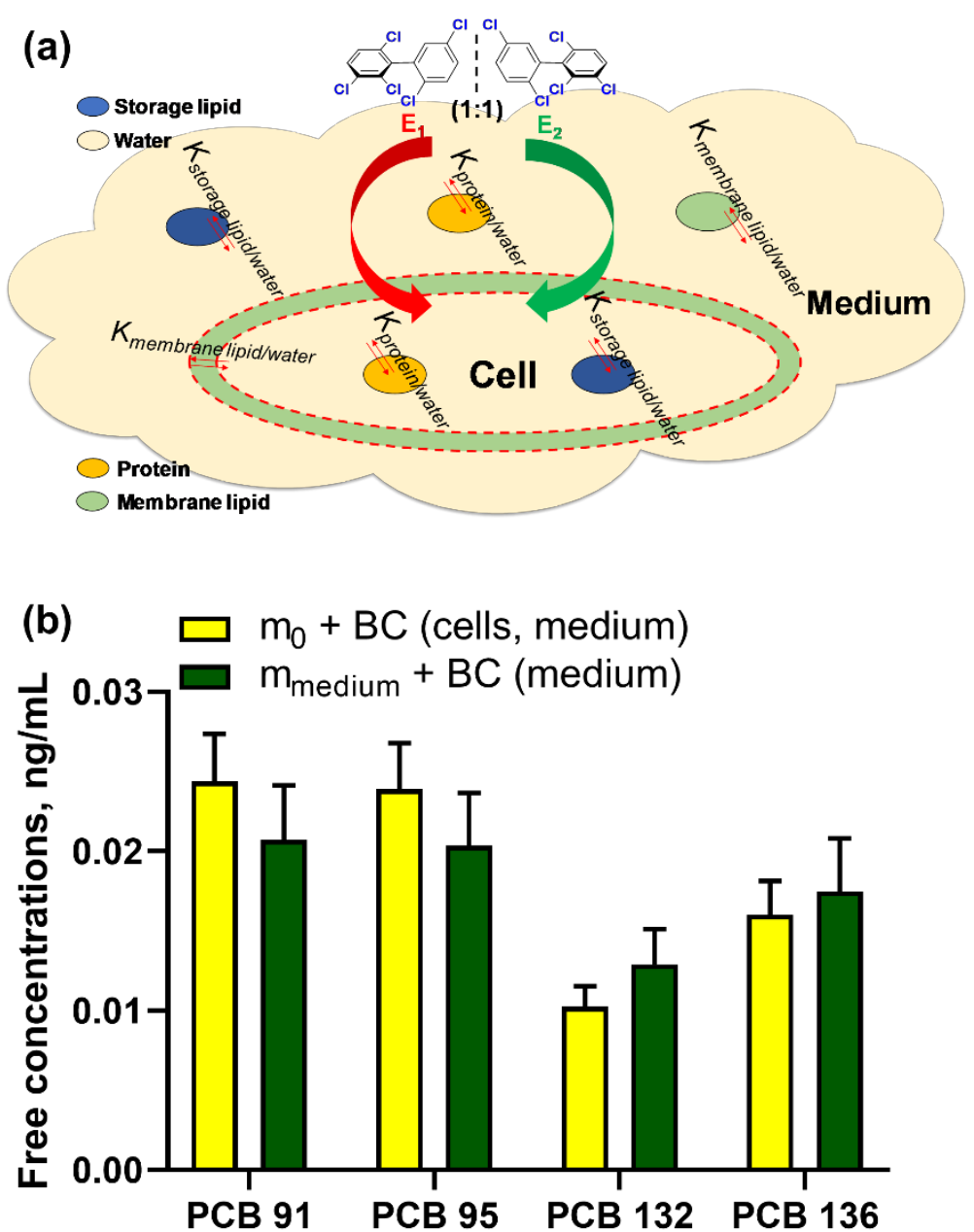

563 Fig. 2. (a) A four-phase, composition-based model was used to describe the distributions of PCB 564 91, PCB 95, PCB 132, and PCB 136 between cell culture medium and cells. (b) Similar free 565 concentrations were estimated with the models using either the initial mass of PCBs $\left(m_{0}\right)$ coupled 566 with biological components (BC) in cells and medium or the measured mass of PCBs $\left(m_{\text {medium }}\right)$ 567 in medium coupled with the BC in the medium. Eqs. (3) and (4) were used for the predictions, 568 respectively. The free concentrations are presented as the average \pm standard deviations of the 569 results obtained with different values for the quantities of biological components in cell culture 570 system (for additional information, see Table S4). 


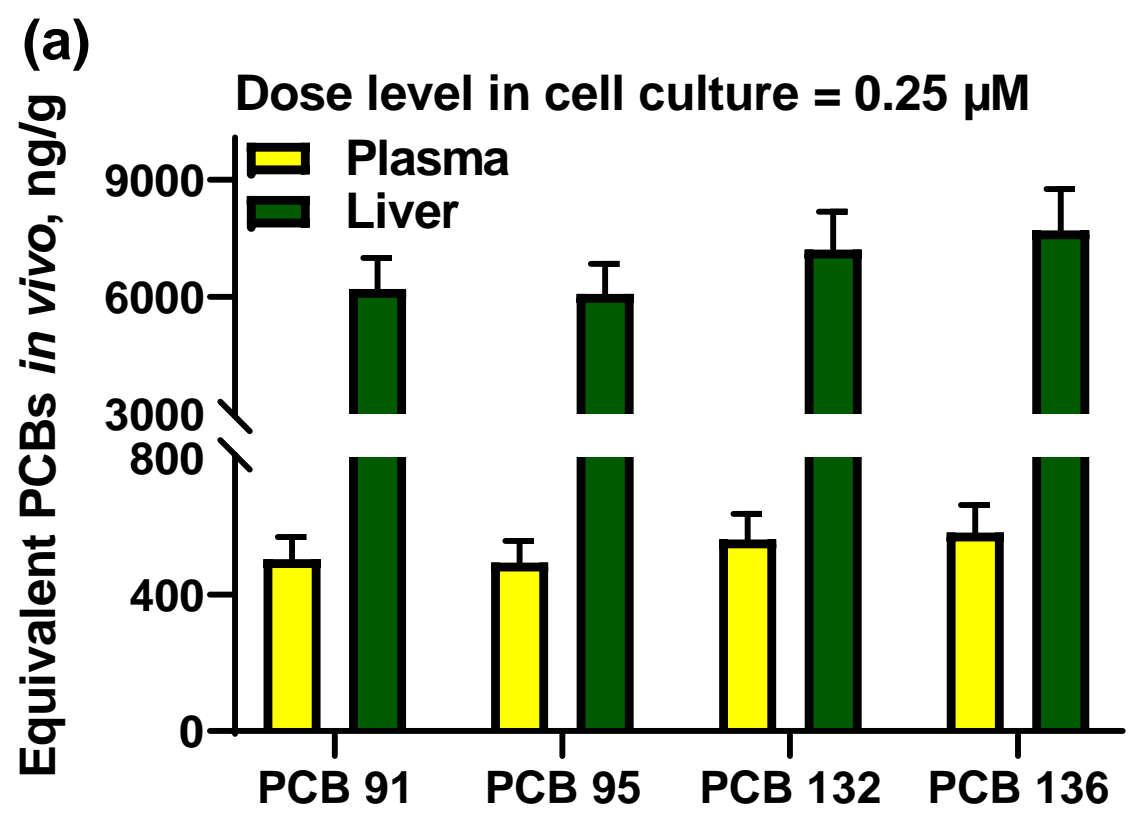

(b)

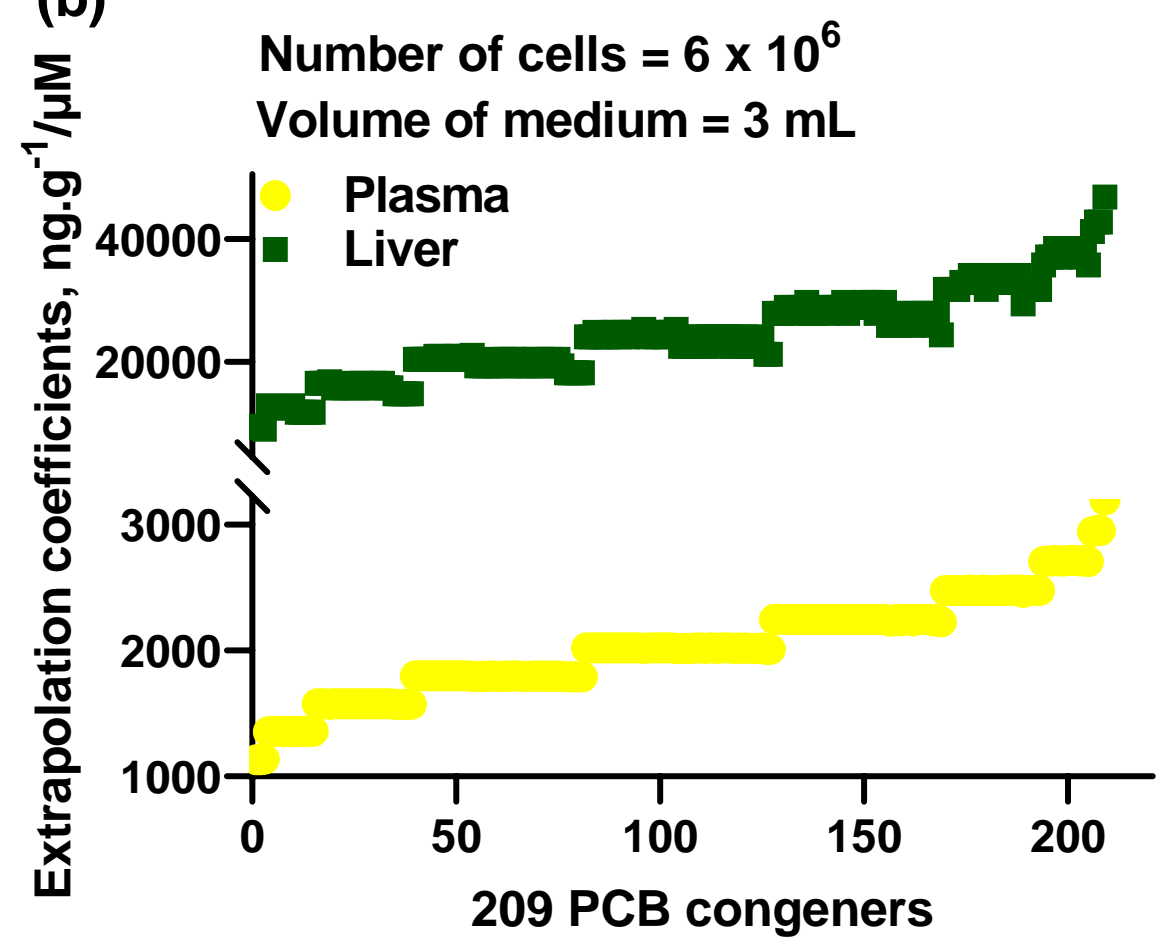

572 Fig. 3. The in vitro-in vivo extrapolation predicted (a) the equivalent in vivo plasma and liver

573 levels of the four PCB congeners studied (PCB 91, PCB 95, PCB 132, and PCB 136)

574 corresponding to $0.25 \mu \mathrm{M}$ dose level in cell culture and (b) the trend of plasma and liver

575 extrapolation coefficients for 209 PCB congeners under the cell culture conditions employed in 
576 this study. Eqs. (5) and (6) were used for the predictions. The equivalent tissue levels of PCB 91,

577 PCB 95, PCB 132, and PCB 136 are presented as the average \pm standard deviations of the results

578 obtained with different values for the quantities of biological components in the cell culture

579 system (for additional information, see Table S4). The extrapolation coefficients of the 209 PCB

580 congeners were given as the average value obtained from various permutations using the data

581 sources listed in Table S4. The solvation parameters of PCBs and the quantities of the biological

582 components in in vivo plasma and liver used for the predictions were obtained from the

583 literature. ${ }^{27,28}$ 


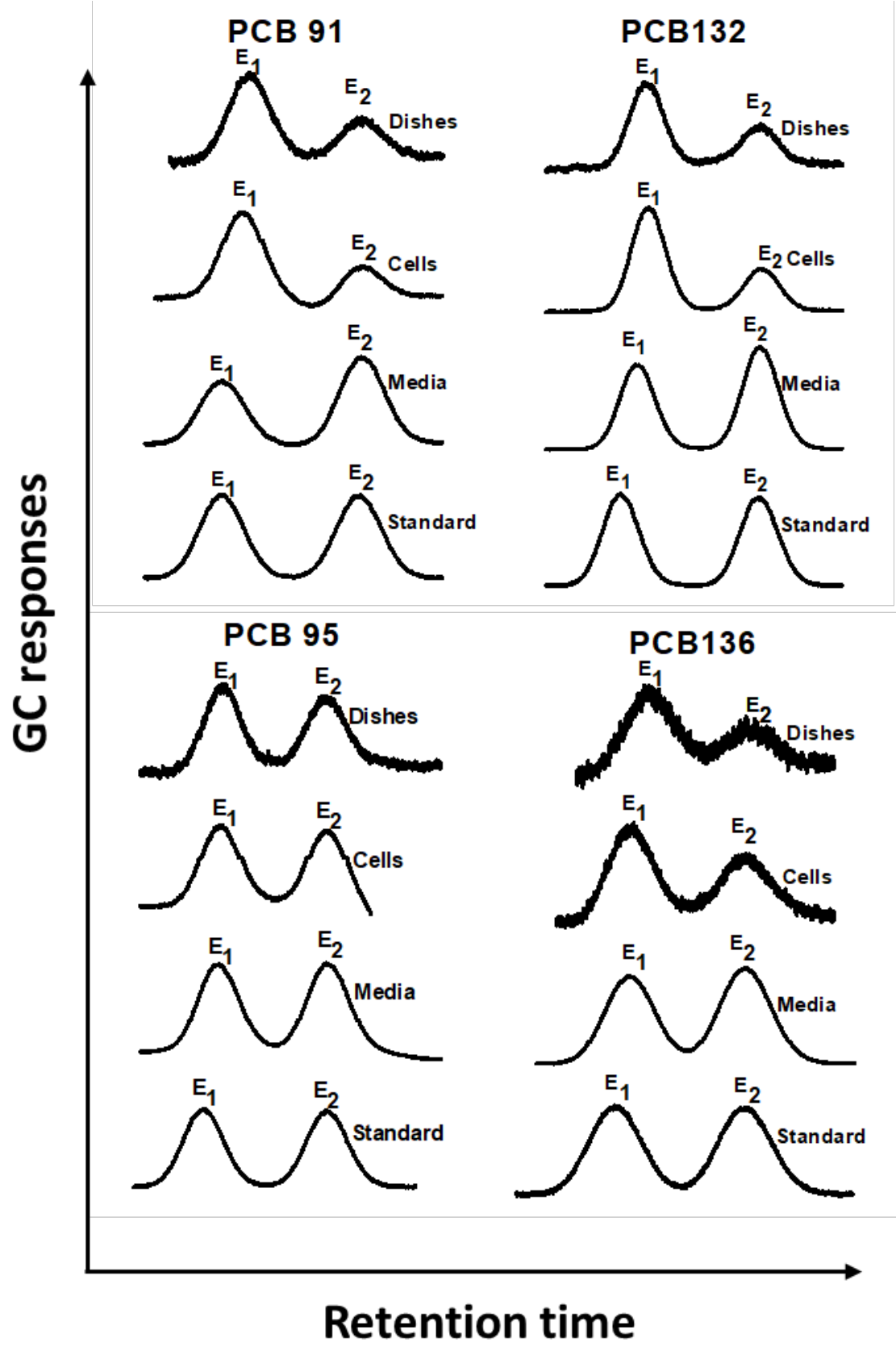

585 Fig. 4. Representative chromatograms show an atropisomeric enrichment in extracts from cell 586 culture media, cell pellet and cell culture dishes after incubation with racemic (a) PCB 91, (b) PCB 587 95, (c) PCB 132 and (d) PCB 136. The atropisomeric enrichment of these parent PCBs occurs in 588 the absence of any detectable metabolism. The racemic PCB standards are shown for comparison. 589 HepG2 cells $\left(6 \times 10^{6}\right.$ /well) were exposed for $72 \mathrm{~h}$ to the individual, racemic PCB congeners (10 
$590 \mu \mathrm{M} ; 0.1 \% \mathrm{DMSO}$ ) in exposure medium (3 mL) with $10 \%$ FBS. After the incubation, the media, 591 cells and cell culture dishes were collected, and enantioselective analyses were performed by GC$592 \mu E C D$ using a CD capillary column as described in the Experimental Section. $E_{1}$ and $E_{2}$ are the 593 atropisomers eluting first and second on the CD capillary column. 
(a)

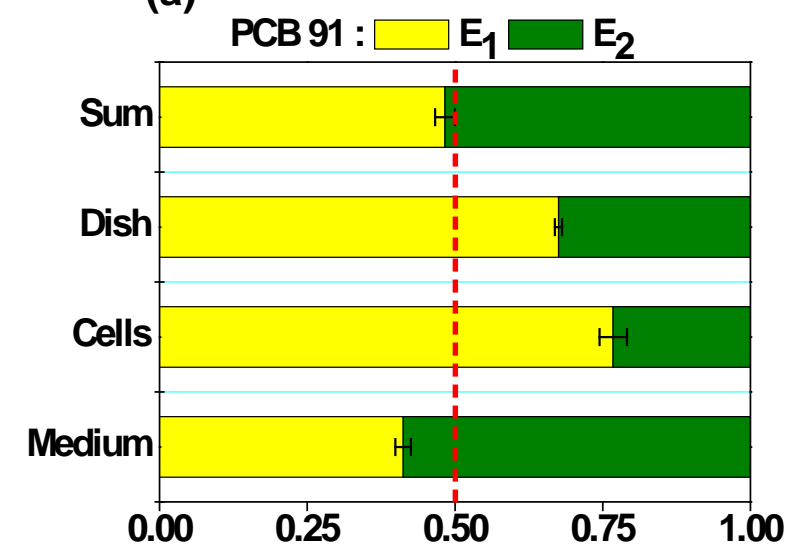

(b)

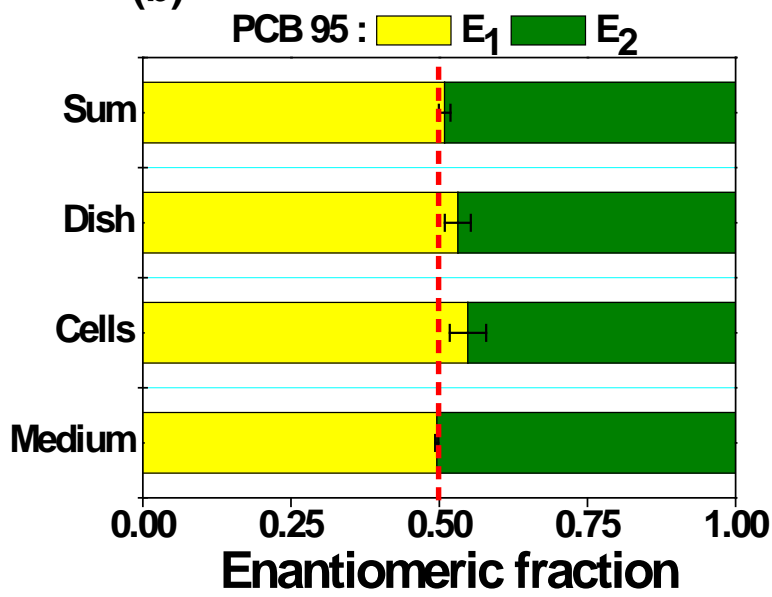

(c)

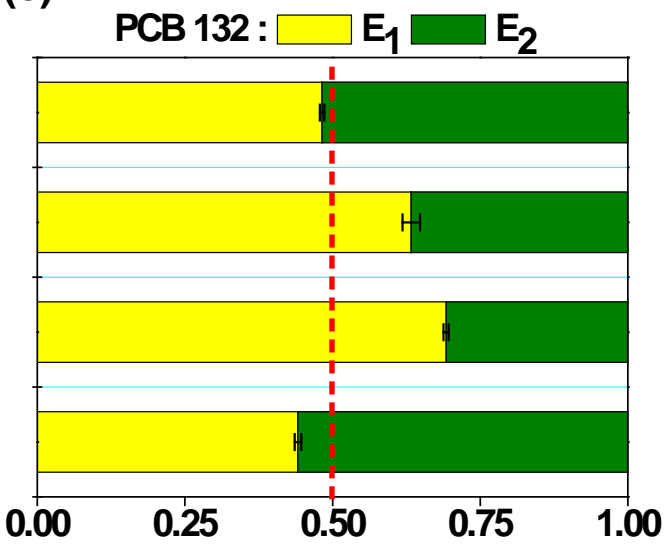

(d)

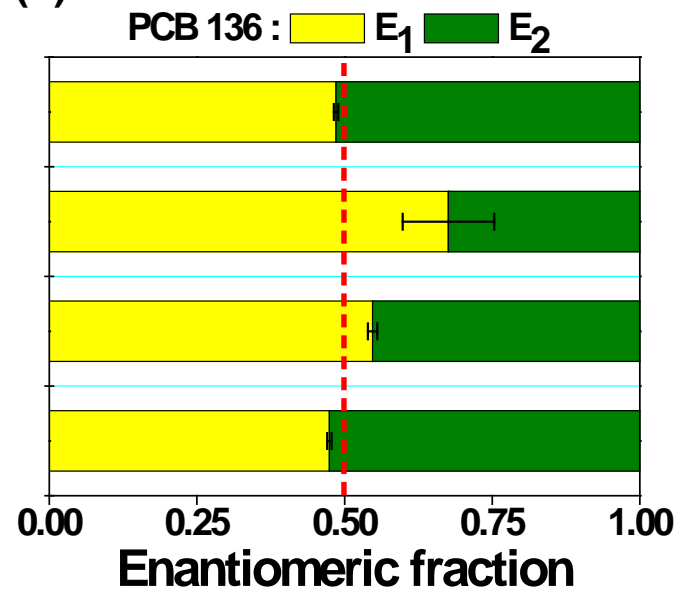

595 Fig. 5. The direction of the atropisomeric enrichment of (a) PCB 91, (b) PCB 95, (c) PCB 132 and

596 (d) PCB 136 in HepG2 cells and cell culture dishes is opposite to the atropisomeric enrichment 597 observed in the cell culture media. HepG2 cells $\left(6 \times 10^{6} /\right.$ well) were exposed for $72 \mathrm{~h}$ to the 598 individual, racemic PCB congeners (10 $\mu \mathrm{M}$; $0.1 \%$ DMSO) in exposure medium (3 mL) with 10 $599 \%$ FBS. After the incubation, the media, cells and cell culture dishes were collected, and 600 enantioselective analyses were performed by GC- $\mu$ ECD using a CD capillary column as described 601 in the Experimental Section. The dotted line indicates the EF value of the respective racemic PCB 602 congener. 


\title{
Enantioselective Partitioning of Polychlorinated
}

\section{Biphenyls in a HepG2 Cell Culture System: Experimental and Modeling Results}

\author{
Chun-Yun Zhang ${ }^{1}$, Susanne Flor ${ }^{1}$, Gabriele Ludewig ${ }^{1}$, Hans-Joachim Lehmler ${ }^{1, *}$ \\ ${ }^{1}$ Department of Occupational and Environmental Health, The University of Iowa, \\ Iowa City, Iowa 52242, United States
}

Corresponding Author:

Dr. Hans-Joachim Lehmler

The University of Iowa

Department of Occupational and Environmental Health

University of Iowa Research Park, B164 MTF

Iowa City, IA 52242-5000

Phone: (319) 335-4981

Fax: (319) 335-4290

e-mail: hans-joachim-lehmler@uiowa.edu

Number of pages: 20

Number of tables: 4

Number of figures: 4 


\section{Table of Content}

Extraction of medium samples and subsequent deconjugation experiments S3

Extraction of medium samples for untargeted analyses $\quad$ S3

Ultra-Performance Liquid Chromatography-Quadrupole Time-of-flight Mass $\quad$ S4

Spectrometric (LC-QTof-MS) analysis

Prediction of the free concentrations of PCBs in the cell culture system S4

In vitro-in vivo extrapolation (IVIVE) S6

Table S1. Summary of the chemical structure, the abbreviation and the source of S8 available hydroxylated or methoxylated standards

Table S2. Comparison of the enantiomeric fractions (EFs) of PCBs in the HepG2 cell culture system determined with different enantioselective columns

Table S3. Quality assurance/quality control (QA/QC) data for the quantitative and chiral analysis of the PCBs

Table S4. The permutations of the system descriptors in HepG2 cell culture system used for the model calculations

Fig. S1. The cytotoxicity of PCBs (PCB 91, PCB 95, PCB 132, and PCB 136) toward HepG2 cells

Fig. S2. Overall extraction workflow of PCBs and their metabolites from the cell culture media, cell pellets and dishes

Fig. S3. The differences in the sorptive capacities (as partition coefficients) of chemicals between storage lipids and membrane lipids

Fig. S4. The partitioning of PCB 91, PCB 95, PCB 132 and PCB 136 in a cell-free culture system

References 


\section{Extraction of medium samples and subsequent deconjugation experiments. PCBs}

and their metabolites were extracted from the medium of HepG2 cells exposed for $72 \mathrm{~h}$ to PCBs (1 $\mu \mathrm{M}$ ) with hexane/MTBE (see Manuscript for additional details regarding the cell culture experiments). The remaining aqueous phase was spiked with 3-F,4'-PCB 3 sulfate (100 ng in methanol), followed by extraction with ethyl acetate (4 mL and $3 \mathrm{~mL})$. Earlier studies have shown that ethyl acetate is an excellent solvent for the extraction of PCB metabolites, including their conjugates, from aqueous media. ${ }^{1}$ 3-F,4'-PCB 3 sulfate (100 ng in methanol) was also added as surrogate recovery standard to blank solvent (buffer) samples. The F-tagged sulfate standard was used to assess the efficiency of the deconjugation of PCB sulfates and the derivatization of the resulting $\mathrm{OH}-\mathrm{PCBs}$ with diazomethane. The combined organic phase was evaporated to dryness and reconstituted in sodium acetate buffer ( $4 \mathrm{~mL}, \mathrm{pH}=5)$. After the addition of sulfatase (type $\mathrm{H}-2$ from Helix pomatia, $50 \mu \mathrm{L}, \geq 2,000$ units/mL), each sample was incubated at $37^{\circ} \mathrm{C}$ for 16 hours to deconjugate PCB conjugates to the corresponding $\mathrm{OH}-\mathrm{PCB}$ metabolites. All samples were extracted, derivatized, and analyzed by GC-ECD as described in the Experimental Section for medium samples. No methoxylated PCBs metabolites were detected in any sample, except for the F-tagged OH-PCB derivative.

\section{Extraction of medium samples from PCB exposed HepG2 cell culture for}

untargeted analyses. Medium samples from HepG2 cells exposed to PCBs ( $1 \mu \mathrm{M})$ for $72 \mathrm{~h}$ were extracted for untargeted analysis (Fig. S2). Briefly, the samples were spiked with 3-F,4'OH PCB 3 and 3-F,4'-PCB 3 sulfate (100 ng each in methanol) as surrogate recovery standards to monitor the performance of the extraction and the untargeted ultra-performance liquid chromatography-quadrupole time-of-flight mass spectrometric (LC-QTof-MS) analyses. Samples were extracted with acetonitrile ( $4 \mathrm{~mL}$ ) after the addition of magnesium sulfate (1.2 $\mathrm{g}$ ) 
and sodium chloride $(0.3 \mathrm{~g})$. The aqueous phase was re-extracted with acetonitrile ( $3 \mathrm{~mL})$. The combined organic phase was passed through a magnesium sulfate (2 g) column to remove water. The extract was evaporated to dryness under a gentle stream of nitrogen and reconstituted in acetonitrile : water (15:85, v/v). LC-QTof MS analysis was performed as described below.

\section{Ultra-Performance Liquid Chromatography-Quadrupole Time-of-flight Mass} Spectrometric (LC-QTof-MS) analysis. The LC-QTof MS analysis was carried out on a Waters Acquity UPLC (Waters, Milford, MA, USA) coupled with a Waters Q-Tof Premier mass spectrometer in the High-Resolution Mass Spectrometry Facility of the University of Iowa (Iowa City, IA, USA). An Acquity BEH C-18 column (2.1 mm inner diameter, 100 mm length, $1.7 \mu \mathrm{m}$ particle size; Waters) was used for the chromatographic separation of potential PCB metabolites, with a flow rate of $0.2 \mathrm{~mL} / \mathrm{min}$. The mobile phase was (A) water with $0.04 \%(\mathrm{v} / \mathrm{v})$ triethylammonium and (B) acetonitrile. The solvent gradient (\% (B)) was as follows: 0-1 min, 15\%; 1-10 min, 15-95 \%, 10-15 min, $95 \%$. The full scan was performed in the ESI ${ }^{-}$mode with a mass-to-charge ratio $(\mathrm{m} / \mathrm{z})$ range from 75 to $800 \mathrm{Da}$ at a rate of $0.2 \mathrm{~s} / \mathrm{scan}$. Leucine enkephalin was infused (10 $\mu \mathrm{L} / \mathrm{min})$ as the lock mass and analyzed separately in ESI ${ }^{-}$mode. The sampling cone voltage was $30 \mathrm{~V}$. The desolvation gas was operated at $350{ }^{\circ} \mathrm{C}$ at a flow rate of $650 \mathrm{~L} / \mathrm{h}$. The capillary voltage was $2.8 \mathrm{kV}$. Full scan raw data were screened for potential penta- or hexachlorinated PCB metabolites, including mono- and di-hydroxylated PCBs, PCB sulfates, PCB glucuronides, and PCB dihydrodiols and their conjugates. ${ }^{2}$ No PCB metabolite was detected in any medium sample.

Prediction of the free concentrations of PCBs in the cell culture system. As shown in Fig. 2a, the PCBs are distributed between the different biological components (i.e., albumin 
protein, storage lipid, membrane lipid, and water) in both medium and cells. The mass balance in the whole system (cell culture dish is excluded), medium and cells can be expressed as

$m_{0}=m_{\text {medium }}+m_{\text {cell }}$

$m_{\text {medium }}=C_{m, a p} V_{m, a p}+C_{m, s l} V_{m, s l}+C_{m, m l} V_{m, m l}+C_{m, w} V_{m, w}$

and

$m_{c e l l}=C_{c, a p} V_{c, a p}+C_{c, s l} V_{c, s l}+C_{c, m l} V_{c, m l}+C_{c, w} V_{c, w}$

respectively. $m_{0}$ is the mass of PCBs initially added in the incubation. $m_{\text {medium }}$ and $m_{\text {cell }}$ are the amounts of PCBs present in the medium and in the cells, respectively. The $m_{0}$ values used for the model calculations in this study were corrected by subtracting the measured levels of PCBs in dishes (about $5.7 \%$ at average). $C_{m, a p}, C_{m, s l}, C_{m, m l}$ and $C_{m, w}$ are the PCBs concentrations in the albumin protein, storage lipid, membrane lipid, and water in medium, respectively. $C_{c, a p}, C_{c, s l}$, $C_{c, m l}$ and $C_{c, w}$ are the PCBs concentrations in the albumin protein, storage lipid, membrane lipid, and water in cells, respectively. $V_{m, a p}, V_{m, s l}, V_{m, m l}$ and $V_{m, w}$ are the volumes of the protein, storage lipid, membrane lipid, and water in medium, respectively. $V_{c, a p}, V_{c, s l}, V_{c, m l}$ and $V_{c, w}$ are the volumes of the albumin protein, storage lipid, membrane lipid, and water in cells, respectively. Assuming a partitioning equilibrium was reached in the system, the partition coefficients between albumin protein $\left(K_{a p, w}\right)$, storage lipid $\left(K_{s l, w}\right)$, membrane lipid $\left(K_{m l, w}\right)$, and water can be expressed as:

$K_{p, w}=\frac{C_{m, a p}}{C_{m, w}}=\frac{C_{c, a p}}{C_{c, w}}$

$K_{s l, w}=\frac{C_{m, s l}}{C_{m, w}}=\frac{C_{c, s l}}{C_{c, w}}$, and

$K_{m l, w}=\frac{C_{m, m l}}{C_{m, w}}=\frac{C_{c, m l}}{C_{c, w}}$

Substituting Eqs. (S-4), (S-5) and (S-6) into Eqs (S-1) and (S-2) gives the following equations: 


$$
\begin{aligned}
& m_{0}=C_{m, w}\left(K_{p, w} V_{m, p}+K_{s l, w} V_{m, s l}+K_{m l, w} V_{m, m l}+V_{m, w}\right) \\
& +C_{c, w}\left(K_{p, w} V_{c, p}+K_{s l, w} V_{c, s l}+K_{m l, w} V_{c, m l}+V_{c, w}\right)
\end{aligned}
$$

and

$m_{\text {medium }}=C_{m, w}\left(K_{p, w} V_{m, p}+K_{s l, w} V_{m, s l}+K_{m l, w} V_{m, m l}+V_{m, w}\right)$

Assuming that free PCB concentrations $\left(C_{\text {free }}\right)$ are equal in the medium $\left(C_{m, w}\right)$ and cells $\left(C_{m, w}\right)$ in the equilibrium state, i.e.,

$C_{\text {free }}=C_{m, w}=C_{c, w}$

Eq. (S-7) and (S-8) can be rearranged to calculate $C_{\text {free }}$ as Eq. (3)

$$
C_{f r e e}=\frac{m_{0}}{K_{a p, w}\left(V_{m, a p}+V_{c, a p}\right)+K_{m l, w}\left(V_{m, m l}+V_{c, m l}\right)+K_{s l, w}\left(V_{m, s l}+V_{c, s l}\right)+V_{m, w}+V_{c, w}}
$$

and as Eq. (4)

$$
C_{f r e e}=\frac{m_{0}}{K_{a p, w} V_{m, a p}+K_{m l, w} V_{m, m l}+K_{s l, w} V_{m, s l}+V_{m, w}}
$$

In vitro-in vivo extrapolation (IVIVE). A composition-based model was used to describe the partitioning of the PCBs in tissues in vivo for the IVIVE. In this model, the biological components in tissues (including plasma) were assumed to be albumin proteins, muscle proteins, storage lipids, membrane lipids, and water. ${ }^{3}$ The mass balance of the PCBs in tissues can be expressed as

$C_{\text {tissue }}=C_{t, a p} f_{t, a p}+C_{t, m p} f_{t, m p}+C_{t, m l} f_{t, m l}+C_{t, s l} f_{t, s l}+C_{t, w} f_{t, w}$

where $C_{t i s s u e}$ is the PCBs concentration in tissue. $C_{t, a p}, C_{t, m p}, C_{t, m l}, C_{t, s l}$ and $C_{t, w}$ are the PCBs concentrations in tissue albumin proteins, muscle proteins, membrane lipids, storage lipids and water, respectively. $f_{t, a p}, f_{t, m p}, f_{t, m l}, f_{t, s l}$ and $f_{t, w}$ are the volume fractions of albumin proteins, muscle proteins, membrane lipids, storage lipids and water in tissue, respectively. 
Assuming the partitioning equilibrium of PCBs in the steady-state tissue, the partitioning coefficients of the PCBs between biological components and water can be expressed as

$K_{a p, w}=\frac{C_{t, a p}}{C_{t, w}}, K_{m p, w}=\frac{C_{t, m p}}{C_{t, w}}, K_{m l, w}=\frac{C_{t, m l}}{C_{t, w}}$, and $K_{s l, w}=\frac{C_{t, s l}}{C_{t, w}}$

where $K_{m p, w}$ is the partitioning coefficient of PCBs between muscle protein and water.

Substituting Eqs. (S-13) into (S-12) gives the following

$C_{\text {tissue }}=C_{t, w}\left(K_{a p, w} f_{t, a p}+K_{m p, w} f_{t, m p}+K_{m l, w} f_{t, m l}+K_{s l, w} f_{t, s l}+f_{t, w}\right)$

To have equal free concentration of PCBs in vitro and in vivo, $C_{f r e e}=C_{c, w}=C_{t, w}$, the equivalent PCBs concentrations in tissues as wet weight, taking liver and plasma as examples, can be calculated as Eq. (5)

$C_{\text {liver }}=C_{\text {free }}\left(K_{a p, w} f_{l, a p}+K_{m p, w} f_{l, m p}+K_{m l, w} f_{l, m l}+K_{s l, w} f_{l, s l}+f_{l, w}\right)$

and as Eq. (6)

$C_{\text {plasma }}=C_{\text {free }}\left(K_{a p, w} f_{p, a p}+K_{m p, w} f_{p, m p}+K_{m l, w} f_{p, m l}+K_{s l, w} f_{p, s l}+f_{p, w}\right)$ 
Table S1. Summary of the chemical structure, abbreviations, and the source of available hydroxylated or methoxylated standards used for the identification of potential OH-PCBs metabolites of PCB 91, PCB 95, PCB 132 and PCB 136.

\begin{tabular}{|l|l|}
\hline \\
\hline
\end{tabular}

Note: The abbreviations for the PCB metabolite standards are based on the nomenclature proposed by Maervoet and co-workers. ${ }^{6}$ 
Table S1-continued. Summary of the chemical structure, abbreviations, and the source of available hydroxylated or methoxylated standards used for the identification of potential $\mathrm{OH}$ PCBs metabolites of PCB 91, PCB 95, PCB 132 and PCB 136.

\begin{tabular}{|l|l|l|}
\hline \\
\hline
\end{tabular}

Note: The abbreviations for the PCB metabolite standards are based on the nomenclature proposed by Maervoet and co-worked. ${ }^{6}$ 
Table S1-continued. Summary of the chemical structure, abbreviations, and the source of available hydroxylated or methoxylated standards used for the identification of potential OHPCBs metabolites of PCB 91, PCB 95, PCB 132 and PCB 136.

\begin{tabular}{|c|c|c|}
\hline Structures & Abbreviation & Source/Reference \\
\hline
\end{tabular}

Note: The abbreviations for the PCB metabolite standards are based on the nomenclature proposed by Maervoet and co-workers. ${ }^{6}$ 
Table S2. Comparison of the enantiomeric fractions (EFs) ${ }^{\mathrm{a}}$ of PCBs in the HepG2 cell culture system determined with different enantioselective columns shows a good concordance of the EF values.

\begin{tabular}{|c|c|c|c|c|}
\hline \multirow{2}{*}{ Samples } & \multirow{2}{*}{ Congeners } & \multicolumn{3}{|c|}{ GC columns for chiral analysis ${ }^{\mathrm{b}}$} \\
\hline & & $\mathrm{CD}^{1}$ & $\mathrm{CD}^{2}$ & $\mathrm{CB}$ \\
\hline \multirow{4}{*}{ Cells } & PCB 91 & $0.77( \pm 0.03)$ & & $0.73( \pm 0.02)$ \\
\hline & PCB 95 & $0.55( \pm 0.03)$ & & $0.50( \pm 0.01)$ \\
\hline & PCB 132 & $0.69( \pm 0.01)$ & $0.72( \pm 0.01)$ & \\
\hline & PCB 136 & $0.55( \pm 0.01)$ & $0.61( \pm 0.02)$ & $0.61( \pm 0.02)$ \\
\hline \multirow{4}{*}{ Dishes } & PCB 91 & $0.68( \pm 0.01)$ & & $0.68( \pm 0.02)$ \\
\hline & PCB 95 & $0.53( \pm 0.02)$ & & $0.51( \pm 0.02)$ \\
\hline & PCB 132 & $0.63( \pm 0.01)$ & $0.70( \pm 0.01)$ & \\
\hline & PCB 136 & $0.68( \pm 0.08)$ & $0.58( \pm 0.03)$ & $0.68( \pm 0.04)$ \\
\hline \multirow{4}{*}{ Media } & PCB 91 & $0.41( \pm 0.02)$ & & $0.41( \pm 0.01)$ \\
\hline & PCB 95 & $0.50( \pm 0.01)$ & & $0.51( \pm 0.01)$ \\
\hline & PCB 132 & $0.44( \pm 0.01)$ & $0.44( \pm 0.01)$ & \\
\hline & PCB 136 & $0.47( \pm 0.01)$ & $0.48( \pm 0.01)$ & $0.48( \pm 0.01)$ \\
\hline \multirow{4}{*}{ Dishes (cell-free) } & PCB 91 & $0.54( \pm 0.01)$ & $0.51( \pm 0.01)$ & $0.51( \pm 0.01)$ \\
\hline & PCB 95 & $0.50( \pm 0.01)$ & $0.51( \pm 0.01)$ & $0.48( \pm 0.02)$ \\
\hline & PCB 132 & $0.47( \pm 0.01)$ & $0.46( \pm 0.01)$ & \\
\hline & PCB 136 & $0.45( \pm 0.01)$ & $0.46( \pm 0.01)$ & $0.45( \pm 0.03)$ \\
\hline \multirow{4}{*}{ Media (cell-free) } & PCB 91 & $0.49( \pm 0.01)$ & & $0.50( \pm 0.02)$ \\
\hline & PCB 95 & $0.50( \pm 0.01)$ & & $0.50( \pm 0.02)$ \\
\hline & PCB 132 & $0.50( \pm 0.01)$ & & \\
\hline & PCB 136 & $0.50( \pm 0.01)$ & & \\
\hline \multirow{4}{*}{ Standards } & PCB 91 & $0.50( \pm 0.01)$ & $0.50( \pm 0.01)$ & $0.50( \pm 0.01)$ \\
\hline & PCB 95 & $0.50( \pm 0.01)$ & $0.50( \pm 0.01)$ & $0.50( \pm 0.01)$ \\
\hline & PCB 132 & $0.50( \pm 0.01)$ & $0.50( \pm 0.01)$ & \\
\hline & PCB 136 & $0.50( \pm 0.01)$ & $0.50( \pm 0.01)$ & $0.50( \pm 0.01)$ \\
\hline
\end{tabular}

${ }^{\mathrm{a}}$ Enantiomeric fractions (EFs) on the $\mathrm{CD}$ were calculated by the valley drop method ${ }^{8}$ as $\mathrm{EF}=$ Area $E_{1} /\left(\right.$ Area $E_{1}+$ Area $\left.E_{2}\right)$, where Area $E_{1}$ and Area $E_{2}$ are the peak areas of the first and second eluting atropisomers. The elution order of the two atropisomers of PCB 91 on the CB column is different from the elution order on the CD column. ${ }^{9}$ To account for the inversion in the elution order and to allow the direct comparison of the EF values, EF values determined on the $\mathrm{CB}$ column are expressed here as $\mathrm{EF}=$ Area $\mathrm{E}_{2} /\left(\right.$ Area $_{1}+$ Area $\left.\mathrm{E}_{2}\right)$.

${ }^{\mathrm{b}}$ Enantioselective analyses of PCBs were performed on an Agilent 6890 gas chromatograph (GC) equipped with a 63Ni- $\mu \mathrm{ECD}$ detector and CP-Chirasil Dex CB (CD) (25 m length, $250 \mu \mathrm{m}$ inner diameter, $0.25 \mu \mathrm{m}$ film thickness; Agilent, Santa Clara, CA, USA) or Cyclosil-B (CB) (30 $\mathrm{m}$ length, $250 \mu \mathrm{m}$ inner diameter, $0.25 \mu \mathrm{m}$ film thickness; Agilent) capillary columns. Analyses were performed with two different $C D$ columns, $C D^{1}$ and $C D^{2}$. Helium was used as carrier gas at a constant flow rate of $3 \mathrm{~mL} / \mathrm{min} .{ }^{10-13}$ The temperature program for the atropselective analysis of PCB 91, PCB 95 and PCB 136 was as follows: initial temperature $50^{\circ} \mathrm{C}$ for $1 \mathrm{~min}, 10^{\circ} \mathrm{C} / \mathrm{min}$ to $140{ }^{\circ} \mathrm{C}$, hold for $170 \mathrm{~min}, 15^{\circ} \mathrm{C} / \mathrm{min}$ to $200^{\circ} \mathrm{C}$, and hold for $20 \mathrm{~min}$. The column temperature 
program for the atropselective analysis of PCB 132 was as follows: initial temperature $50{ }^{\circ} \mathrm{C}$ for $1 \mathrm{~min}, 10^{\circ} \mathrm{C} / \mathrm{min}$ to $160{ }^{\circ} \mathrm{C}$, hold for $140 \mathrm{~min}, 15^{\circ} \mathrm{C} / \mathrm{min}$ to $200^{\circ} \mathrm{C}$, and hold for $20 \mathrm{~min}$. 
Table S3. Quality assurance/quality control (QA/QC) data for the quantitative and chiral analysis of the PCBs.

\begin{tabular}{|c|c|c|c|c|c|}
\hline QA/QC data & $\begin{array}{l}\text { Sample type (number of } \\
\text { samples) }\end{array}$ & РCB 91 & PCB 95 & PCB 132 & PCB 136 \\
\hline $\begin{array}{l}\text { Linear range }^{\mathrm{a}} \\
{[\mathrm{ng} / \mathrm{mL}]}\end{array}$ & Standards $(\mathrm{n}=8)$ & $1-1000$ & $1-1000$ & $1-1000$ & $1-1000$ \\
\hline \multirow{2}{*}{ LODs $^{\mathrm{b}}[\mathrm{ng}]$} & Media and cells $(n=5)$ & 0.5 & 0.3 & 0.1 & 0.8 \\
\hline & Dishes $(n=2)$ & 0.09 & 0.06 & 0.04 & 0.06 \\
\hline \multirow{3}{*}{$\begin{array}{l}\text { Background } \\
\text { levels }^{\mathrm{C}}[\mathrm{ng}]\end{array}$} & Media $(n=9)$ & $0.8( \pm 0.7)$ & $1.2( \pm 1.7)$ & $0.2( \pm 0.3)$ & $0.5( \pm 0.3)$ \\
\hline & Cells $(n=9)$ & $0.5( \pm 0.8)$ & $2.8( \pm 3.2)$ & $0.1( \pm 0.1)$ & $0.8( \pm 1.4)$ \\
\hline & Dishes $(n=8)$ & $0.4( \pm 0.4)$ & $0.6( \pm 0.5)$ & $0.4( \pm 0.4)$ & $0.8( \pm 0.9)$ \\
\hline \multirow{3}{*}{$\begin{array}{l}\text { Recoveries of } \\
\text { PCB } 117^{\mathrm{d}} \text { [\%] }\end{array}$} & Media $(n=45)$ & \multicolumn{4}{|c|}{$88( \pm 8)$} \\
\hline & Cells $(n=21)$ & \multicolumn{4}{|c|}{$82( \pm 6)$} \\
\hline & Dishes $(n=32)$ & \multicolumn{4}{|c|}{$62( \pm 9)$} \\
\hline Resolution $^{\mathrm{e}}$ & Racemic standards $(\mathrm{n}=4)$ & $\begin{array}{c}0.90 \\
( \pm 0.06)\end{array}$ & $\begin{array}{c}0.87 \\
( \pm 0.06)\end{array}$ & $\begin{array}{c}0.98 \\
( \pm 0.06)\end{array}$ & $\begin{array}{c}0.79 \\
( \pm 0.09)\end{array}$ \\
\hline EF value $^{\mathrm{f}}$ & Racemic standards $(n=3)$ & $\begin{array}{c}0.50 \\
( \pm 0.01)\end{array}$ & $\begin{array}{c}0.50 \\
( \pm 0.01)\end{array}$ & $\begin{array}{c}0.50 \\
( \pm 0.01)\end{array}$ & $\begin{array}{c}0.50 \\
( \pm 0.01)\end{array}$ \\
\hline
\end{tabular}

${ }^{\text {a }}$ The linear coefficients $\left(\mathrm{R}^{2}\right)$ of the calibration curves in a concentration range from 1 to 1000 $\mathrm{ng} / \mathrm{mL}$ ranged from 0.998 to 0.999 for all the PCBs, including the surrogate standard (PCB 117) and internal standard (PCB 204).

${ }^{\mathrm{b}}$ The limits of detection (LOD) of PCBs were calculated from method blanks as LOD = mean blanks $+3 \times$ standard deviation blanks. ${ }^{14,15}$

${ }^{\mathrm{c}}$ The background PCB levels in media, cells, and dishes were calculated from all control samples incubated in parallel with PCBs exposed samples.

${ }^{\mathrm{d}}$ Recoveries of the surrogate recovery standard (PCB 117) from the media, cells, or dish samples.

e The resolution of the PCB atropisomers $\left(\mathrm{R}_{S}\right)$ on the CD column were calculated as: $R_{S}=$ $\left(t_{R_{1}}-t_{R_{2}}\right) / 0.5\left(B W_{1}-B W_{2}\right)$, where $t_{R_{1}}$ and $t_{R_{2}}$ are the retention times of the first and second eluting atropisomers, respectively, and BW1 and BW2 are the baseline width of the first and second eluting atropisomers. ${ }^{16}$

${ }^{\mathrm{f}}$ The enantiomeric fraction (EF) of the racemic PCB standards on CD column were calculated as $\mathrm{EF}=$ Area $\mathrm{E}_{1} /$ Area $\mathrm{E}_{1}+$ Area $\mathrm{E}_{2}$. 
Table S4. The permutations of the system descriptors in HepG2 cell culture system used for the model calculations. ${ }^{\mathrm{a}}$

\begin{tabular}{|c|c|c|c|c|}
\hline Items & $\begin{array}{c}\text { Albumin protein } \\
\text { content } \\
\left(V_{m, a p}, \mu \mathrm{L} / \mathrm{mL}\right) \\
\text { or } \\
\left(V_{c, a p}, \mu \mathrm{L} / 10^{6} \text { cells }\right)\end{array}$ & $\begin{array}{c}\text { Storage lipid } \\
\text { content } \\
\left(V_{m, s l}, \mu L / m L\right) \\
\text { or } \\
\left(V_{c, s l}, \mu \mathrm{L} / 10^{6} \text { cells }\right)\end{array}$ & $\begin{array}{c}\text { Membrane lipid } \\
\text { content } \\
\left(V_{m, m l}, \mu \mathrm{L} / \mathrm{mL}\right) \\
\text { or } \\
\left(V_{c, m l}, \mu \mathrm{L} / 10^{6} \text { cells }\right)\end{array}$ & $\begin{array}{c}\text { Water content } \\
\left(V_{m, w}, \mu \mathrm{L} / \mathrm{mL}\right) \\
\text { or } \\
\text { ( } V_{c, w}, \\
\left.\mu \mathrm{L} / 10^{6} \text { cells }\right)\end{array}$ \\
\hline MEM & 1.59 & $0^{\mathrm{b}}$ & $0^{\mathrm{b}}$ & 998.4 \\
\hline \multirow{4}{*}{ FBS } & \multirow{4}{*}{27.1} & \multirow{2}{*}{$0.719^{17}$} & $0.566^{18}$ & 971.6 \\
\hline & & & 2.81 & 969.4 \\
\hline & & \multirow{2}{*}{$1.162^{18}$} & $0.566^{18}$ & 971.1 \\
\hline & & & 2.81 & 968.9 \\
\hline \multirow{2}{*}{ HepG2 } & \multirow{2}{*}{0.287} & $0.0224^{19}$ & \multirow{2}{*}{0.0969} & 2.65 \\
\hline & & $0.0324^{20}$ & & 2.65 \\
\hline
\end{tabular}

${ }^{a}$ Values without citation were obtained from reference ${ }^{21}$. The values for the densities of protein, storage lipid, membrane lipid, and water were 1.4, 0.93, 1 and $1 \mathrm{mg} / \mu \mathrm{L}$, respectively. ${ }^{3}$ Based on the data sources, there are four permutations of the biological components for medium (MEM plus FBS), and there are two permutations of the biological components for HepG2 cells. Therefore, eight permutations were used for the model calculations referring to the standard deviations in Fig. 2b and 3a and the averages in Fig. 3b.

${ }^{\mathrm{b}}$ A value of zero was assumed for the lipid contents in the medium because the minimum essential medium (MEM) contains only a negligible amount of lipid. 
(a)

resazurin after $72 \mathrm{~h}$

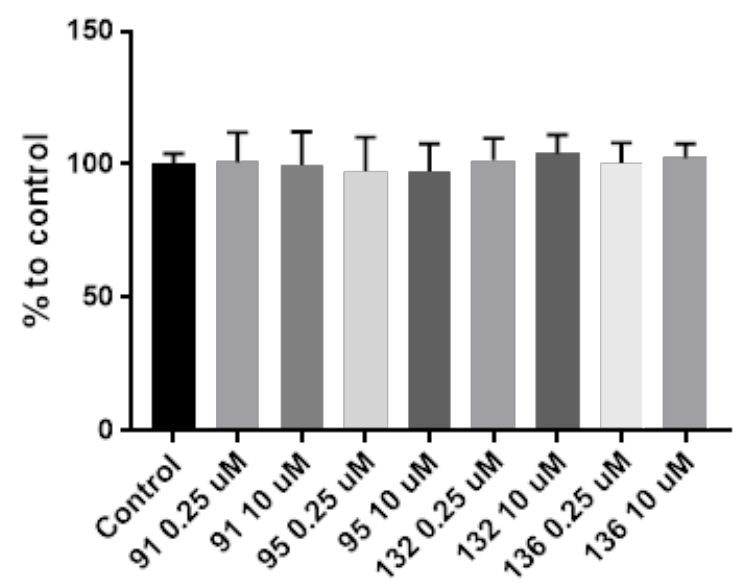

(b) Cell count after $72 \mathrm{~h}$

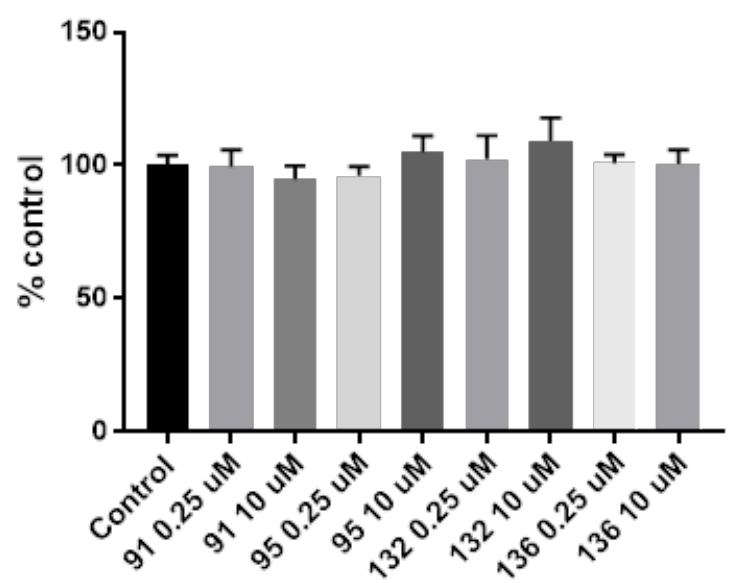

Fig. S1. The cytotoxicity of PCBs (PCB 91, PCB 95, PCB 132, and PCB 136) toward HepG2 cells by (a) resazurin method and (b) cell count method reveals no toxiciy at the concentrations investigated $(0.25$ and $10 \mu \mathrm{M})$. Briefly, HepG2 cells in 24-well plates with serum-free MEM were exposed to $0,0.25$ and $10 \mu \mathrm{M}$ PCB ( $0.1 \%$ DMSO final concentration) for $72 \mathrm{~h}$. Cells were either incubated with resazurin $(50 \mu \mathrm{M})$ in complete medium for 45 min after which fluorescence was measured with a microplate reader (resazurin assay) or detached and counted by Flow Cytometry (cell count). The assay was performed in duplicates at least 3-times, and the results are plotted as percent of control. 


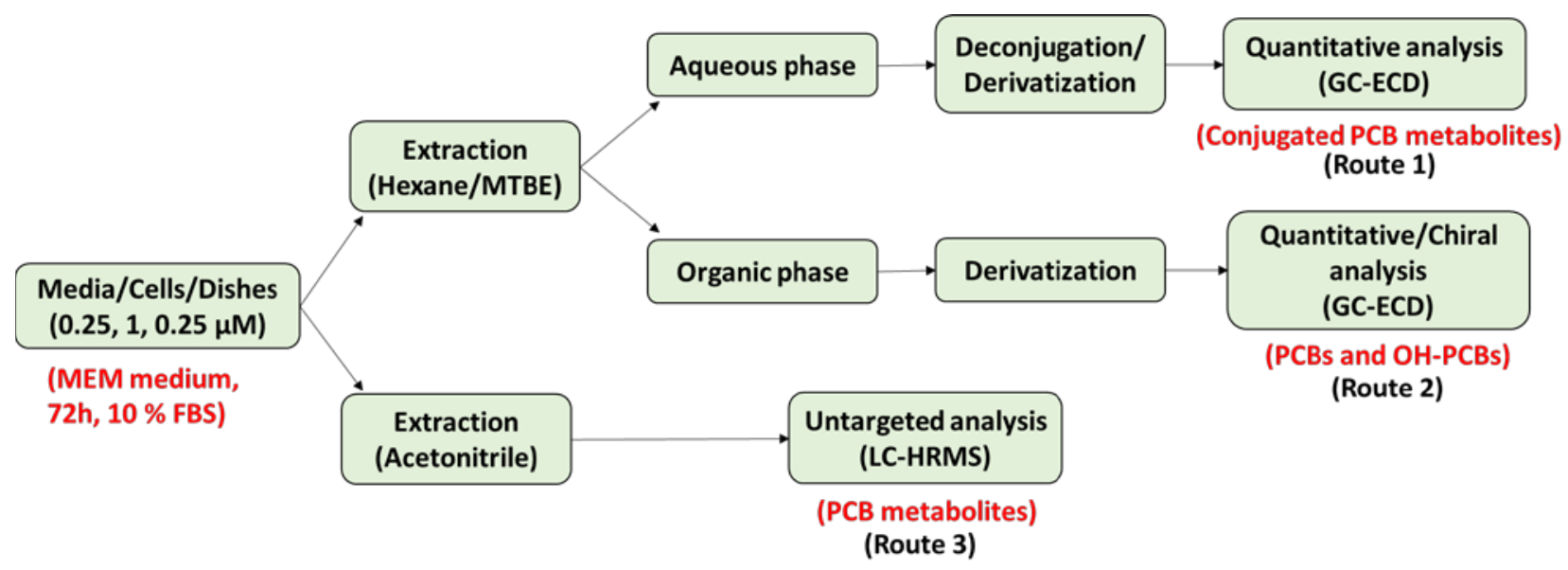

Fig. S2. Overall extraction workflow of PCBs and their metabolites from cell culture media, cell pellets, and dishes. 


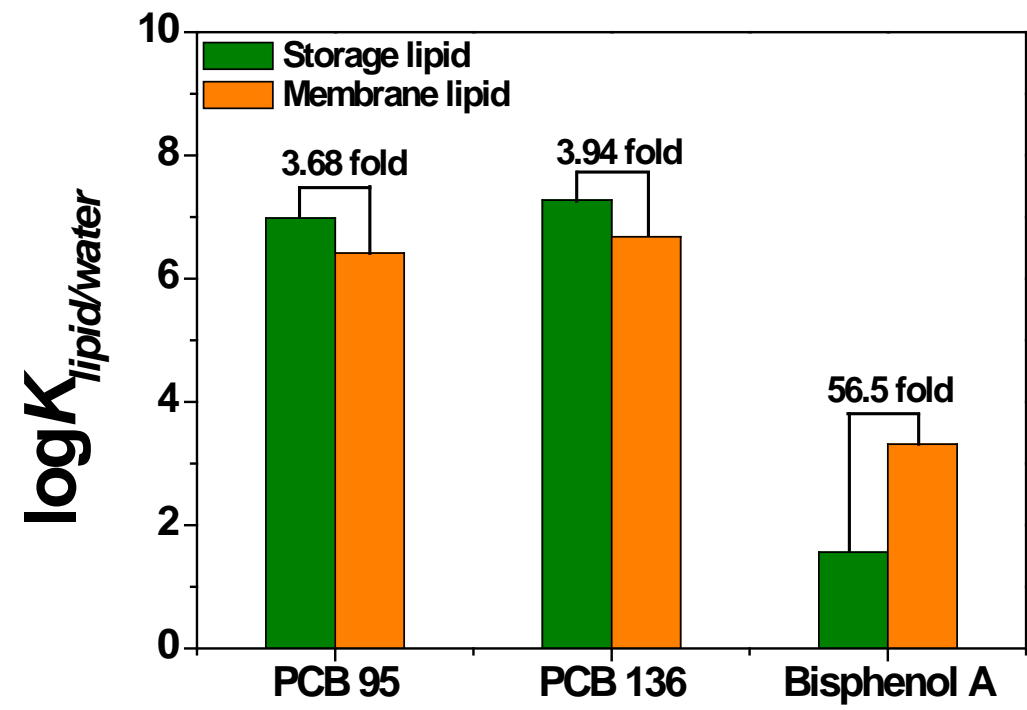

Fig. S3. The polyparameter linear free energy relationships (PP-LFER) ${ }^{3}$ predicted significant differences in the sorptive capacities (as partition coefficients) between storage lipids and membrane lipids for two PCBs, with the sorptive capacity being higher in storage than membrane lipids. In contrast, polar compounds, such as bisphenol A, have a higher sorptive capacity in the membrane than storage lipids. 

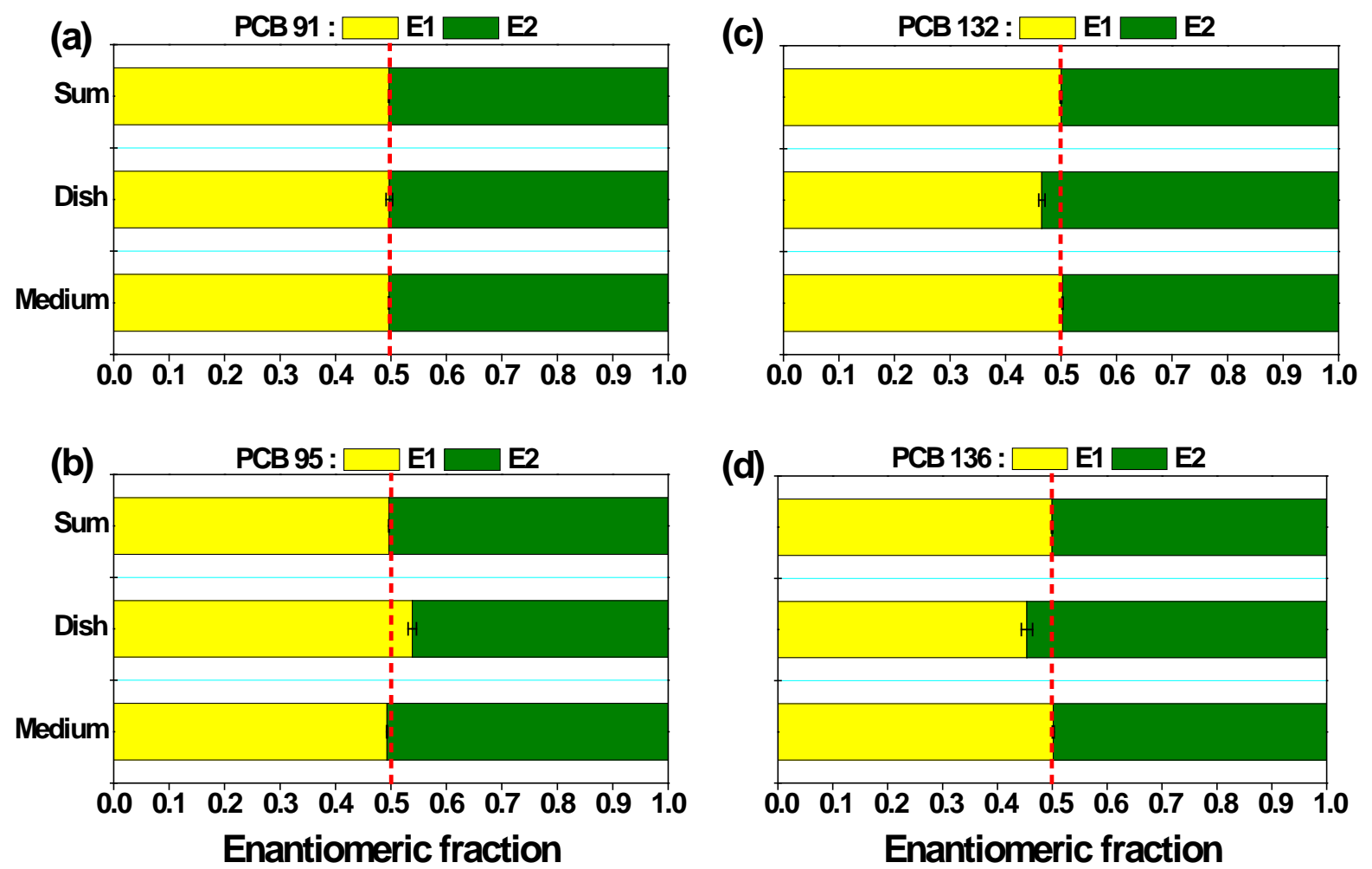

Fig. S4. The partitioning of (a) PCB 91, (b) PCB 95, (c) PCB 132 and (d) PCB 136 in a cell-free incubations is not enantioselective. The moderate atropisomeric enrichment observed in extracts from several cell culture dishes is likely due to the experimental error associated with the chiral analysis of samples with low PCB concentrations. Cell culture wells were incubated for $72 \mathrm{~h}$ with PCBs $(0.25 \mu \mathrm{M})$ in serum-free MEM, and the media and cell culture dish samples were extracted as described for incubations with HepG2 cells in the Experimental section.

Enantiomeric fractions (EFs) on the CD column were calculated by the valley drop method ${ }^{8}$ as $E F=$ Area $E_{1} /\left(\right.$ Area $E_{1}+$ Area $\left.E_{2}\right)$, where Area $E_{1}$ and Area $E_{2}$ are the peak areas of the first and second eluting atropisomers. The elution order of the two atropisomers of PCB 91 on the CB column is different from the elution order on the CD column. ${ }^{9}$ To account for the inversion in the elution order and to allow the direct comparison of the EF values, EF values determined on the $\mathrm{CB}$ column are expressed here as $\mathrm{EF}=$ Area $\mathrm{E}_{2} /\left(\right.$ Area $_{1}+$ Area $\left.\mathrm{E}_{2}\right)$. Enantioselective analyses of PCBs were performed on an Agilent 6890 gas chromatograph (GC) equipped with a 63Ni$\mu \mathrm{ECD}$ detector and CP-Chirasil Dex CB (CD) (25 m length, $250 \mu \mathrm{m}$ inner diameter, $0.25 \mu \mathrm{m}$ film thickness; Agilent, Santa Clara, CA, USA). Helium was used as carrier gas at a constant flow rate of $3 \mathrm{~mL} / \mathrm{min}^{10-13}$ The temperature program for the atropselective analysis of PCB 91, PCB 95 and PCB 136 was as follows: initial temperature $50{ }^{\circ} \mathrm{C}$ for $1 \mathrm{~min}, 10^{\circ} \mathrm{C} / \mathrm{min}$ to $140{ }^{\circ} \mathrm{C}$, hold for $170 \mathrm{~min}, 15^{\circ} \mathrm{C} / \mathrm{min}$ to $200{ }^{\circ} \mathrm{C}$, and hold for $20 \mathrm{~min}$. The column temperature program for the atropselective analysis of PCB 132 was as follows: initial temperature $50^{\circ} \mathrm{C}$ for $1 \mathrm{~min}, 10$ ${ }^{\circ} \mathrm{C} / \mathrm{min}$ to $160{ }^{\circ} \mathrm{C}$, hold for $140 \mathrm{~min}, 15^{\circ} \mathrm{C} / \mathrm{min}$ to $200^{\circ} \mathrm{C}$, and hold for $20 \mathrm{~min}$. 


\section{References}

1. McLean, M.R.; Robertson, L.W.; Gupta, R.C. Detection of PCB adducts by the P-32-Postlabeling technique. Chem Res Toxicol 1996, 9, 165-171.

2. Wu, X.; Zhai, G.; Schnoor, J.L.; Lehmler, H.J. Atropselective disposition of 2,2',3,4',6pentachlorobiphenyl (PCB 91) and identification of its metabolites in mice with liver-specific deletion of cytochrome P450 reductase. Chem Res Toxicol 2019.

3. Endo, S.; Brown, T.N.; Goss, K.U. General model for sstimating partition coefficients to organisms and their tissues using the biological compositions and polyparameter linear free energy relationships. Environ Sci Technol 2013, 47, 6630-6639.

4. Joshi, S.N.; Vyas, S.M.; Duffel, M.W.; Parkin, S.; Lehmler, H.J. Synthesis of sterically hindered polychlorinated biphenyl derivatives. Synthesis 2011, 1045-1054.

5. Kania-Korwel, I.; Vyas, S.M.; Song, Y.; Lehmler, H.J. Gas chromatographic separation of methoxylated polychlorinated biphenyl atropisomers. J Chromatogr A 2008, 1207, 146-154.

6. Maervoet, J.; Covaci, A.; Schepens, P.; Sandau, C.D.; Letcher, R.J. A reassessment of the nomenclature of polychlorinated biphenyl (PCB) metabolites. Environ Health Persp 2004, 112, 291-294.

7. Waller, S.C.; He, Y.A.; Harlow, G.R.; He, Y.Q.; Mash, E.A.; Halpert, J.R. 2,2 ',3,3 ',6,6 'hexachlorobiphenyl hydroxylation by active site mutants of cytochrome P4502B1 and 2B11. Chem Res Toxicol 1999, 12, 690-699.

8. $\quad$ Asher, B.J.; D'Agostino, L.A.; Way, J.D.; Wong, C.S.; Harynuk, J.J. Comparison of peak integration methods for the determination of enantiomeric fraction in environmental samples. Chemosphere 2009, 75, 1042-1048.

9. Kania-Korwel, I.; Lehmler, H.J. Assigning atropisomer elution orders using atropisomerically enriched polychlorinated biphenyl fractions generated by microsomal metabolism. J Chromatogr A 2013, 1278, 133-144. 
10. Uwimana, E.; Li, X.S.; Lehmler, H.J. 2,2 ',3,5 ',6-Pentachlorobiphenyl (PCB 95) is atropselectively metabolized to para-hydroxylated metabolites by human liver microsomes. Chem Res Toxicol 2016, 29, 2108-2110.

11. Uwimana, E.; Maiers, A.; Li, X.S.; Lehmler, H.J. Microsomal metabolism of prochiral polychlorinated biphenyls results in the enantioselective formation of chiral metabolites. Environ Sci Technol 2017, 51, 1820-1829.

12. Uwimana, E.; Li, X.S.; Lehmler, H.J. Human liver microsomes atropselectively metabolize 2,2 ',3,4 ',6-pentachlorobiphenyl (PCB 91) to a 1,2-shift product as the major metabolite. Environ Sci Technol 2018, 52, 6000-6008.

13. Uwimana, E.; Cagle, B.; Yeung, C.; Li, X.S.; Patterson, E.V.; Doorn, J.A.; Lehmler, H.J. Atropselective oxidation of 2,2 ',3,3 ',4,6 '-hexachlorobiphenyl (PCB 132) to hydroxylated metabolites by human liver microsomes and its implications for PCB 132 neurotoxicity. Toxicol Sci 2019, 171, 406-420.

14. Marek, R.F.; Thome, P.S.; Herkert, N.J.; Awad, A.M.; Hornbuckle, K.C. Airborne PCBs and OH-PCBs Inside and Outside Urban and Rural US Schools. Environ Sci Technol 2017, 51, 78537860.

15. Persoon, C.; Peters, T.M.; Kumar, N.; Hornbuckle, K.C. Spatial distribution of airborne polychlorinated biphenyls in Cleveland, Ohio and Chicago, Illinois. Environ Sci Technol 2010, 44, 2797-2802.

16. Wu, X.A.; Pramanik, A.; Duffel, M.W.; Hrycay, E.G.; Bandiera, S.M.; Lehmler, H.J.; KaniaKorwel, I. 2,2 ',3,3 ',6,6 '-Hexachlorobiphenyl (PCB 136) is enantioselectively oxidized to hydroxylated metabolites by rat Liver microsomes. Chem Res Toxicol 2011, 24, 2249-2257.

17. Cheever, M.; Master, A.; Versteegen, R.J. A method for differentiating fetal bovine serum from newborn calf serum. BioProcessing Journal 2017, 16.

18. Villard, P.H.; Barlesi, F.; Armand, M.; Dao, T.M.A.; Pascussi, J.M.; Fouchier, F.; Champion, S.; Dufour, C.; Ginies, C.; Khalil, A.; Amiot, M.J.; Barra, Y.; Seree, E. CYP1A1 induction in the 
colon by serum: involvement of the PPAR alpha pathway and evidence for a new specific human PPRE alpha site. Plos One 2011, 6.

19. Zhu, X.P.; Yan, H.M.; Xia, M.F.; Chang, X.X.; Xu, X.; Wang, L.; Sun, X.Y.; Lu, Y.; Bian, H.; Li, X.Y.; Gao, X. Metformin attenuates triglyceride accumulation in HepG2 cells through decreasing stearyl-coenzyme A desaturase 1 expression. Lipids Health Dis 2018, 17.

20. Burdeos, G.C.; Nakagawa, K.; Kimura, F.; Miyazawa, T. Tocotrienol attenuates triglyceride accumulation in HepG2 cells and F344 rats. Lipids 2012, 47, 471-481.

21. Fischer, F.C.; Henneberger, L.; Konig, M.; Bittermann, K.; Linden, L.; Goss, K.U.; Escher, B.I. Modeling exposure in the Tox21 in vitro bioassays. Chem Res Toxicol 2017, 30, 1197-1208. 